\title{
Neurexins Regulate GABA Co-release by Dopamine Neurons
}

\author{
Charles Ducrot ${ }^{1,2,3}$, Gregory de Carvalho ${ }^{4}$, Benoît Delignat-Lavaud ${ }^{1,2,3}$, Constantin V.L. \\ Delmas $^{5}$, Nicolas Giguère ${ }^{1,2,3}$, Sriparna Mukherjee ${ }^{1,2,3}$, Samuel Burke-Nanni ${ }^{1,2,3}$, Marie-Josée \\ Bourque $^{1,2,3}$, Martin Parent ${ }^{5}$, Lulu Y. Chen ${ }^{4 *}$ and Louis-Éric Trudeau ${ }^{1,2,3 *}$
}
${ }^{1}$ Department of Pharmacology and Physiology, Faculty of Medicine, Université de Montréal
${ }^{2}$ Department of Neurosciences, Faculty of Medicine, Université de Montréal
${ }^{3}$ Neural Signaling and Circuitry Research Group (SNC),
Montréal, QC, Canada H3C 3J7
${ }^{4}$ Department of Anatomy and Neurobiology,
School of Medicine, University of California,
Irvine, CA, USA 92697
CERVO Brain Research Centre, Department of Psychiatry and Neurosciences,
Faculty of Medicine, Université Laval
${ }^{*}$ Co-corresponding authors

\author{
Contact information: \\ Dr. Louis-Éric Trudeau \\ louis-eric.trudeau@umontreal.ca \\ Phone: 514-343-5692 \\ Dr. Lulu Y. Chen \\ chenly@uci.edu \\ Phone: 949-824-3503
}




\section{Summary}

Midbrain dopamine (DA) neurons are key regulators of basal ganglia functions. The axonal domain of these neurons is highly complex, with a large subset of non-synaptic release sites and a smaller subset of synaptic terminals from which glutamate or GABA are released. The molecular mechanisms regulating the connectivity of DA neurons and their neurochemical identity are unknown. Here we tested the hypothesis that the trans-synaptic cell adhesion molecules neurexins (Nrxns) regulate DA neuron neurotransmission. Conditional deletion of all Nrxns in DA neurons (DAT::Nrxns KO) showed that loss of Nrxns does not impair the basic development and ultrastructural characteristics of DA neuron terminals. However, loss of Nrxns caused an impairment of DA transmission revealed as a reduced rate of DA reuptake following activitydependent DA release, decreased DA transporter levels, increased vesicular monoamine transporter expression, and impaired amphetamine-induced locomotor activity. Strikingly, electrophysiological recording revealed an increase of GABA co-release from DA neuron axons in the striatum of the KO mice. These findings suggest that Nrxns act as key regulators of DA neuron connectivity and DA-mediated functions.

\section{Highlights}

- The study provides the first direct evidence of the role of neurexins in dopaminergic neurons.

- The synaptic adhesion molecules, neurexins, are not required for maintaining the structure of dopamine neuron terminals.

- Neurexins regulate dopaminergic neurotransmission through regulation of dopamine reuptake, impacting amphetamine-induced locomotion.

- Deletion of Nrxns in DA neurons causes a region-specific increase of GABA release by DA neurons. 


\section{Introduction}

Dopamine (DA) neurons from the ventral tegmental area (VTA) and substantia nigra pars compacta (SNc) project densely to the ventral striatum (VS) and to the dorsal striatum (DS), respectively (Descarries et al., 1980; Matsuda et al., 2009) and are critical regulators of basal ganglia functions, motivation, and cognition (Schultz, 2007; Surmeier et al., 2014). The connectivity of the DA system is predominantly non-synaptic (Descarries et al., 2008; Ducrot et al., 2021), with a majority of DA-releasing terminals not located in close apposition to a postsynaptic domain (Caille et al., 1996; Descarries et al., 1996; Descarries and Mechawar, 2000; Descarries et al., 2008; Ducrot et al., 2021). A smaller synaptic subset of DA neuron terminals has the ability to co-release glutamate or GABA (Sulzer et al., 1998; Dal Bo et al., 2004; Mendez et al., 2008; Stuber et al., 2010; Tritsch et al., 2012; Tritsch et al., 2016). The molecular mechanisms underlying the formation and regulation of non-synaptic terminals is presently undetermined. Interestingly, a growing body of work has highlighted the functional role of trans-synaptic cell adhesion molecules such as the neurexins (Nrxns) and neuroligins (NLs) in orchestrating synaptic functions and plasticity at synaptic terminals (Zhang et al 2015, Chen et al, 2017).

Nrxns are presynaptic cell adhesion molecules that were identified as $\alpha$-latrotoxin receptors (Ushkaryov et al., 1992). In mammals, Nrxns are expressed in two principal forms: longer $\alpha$ neurexins isoforms and shorter ß-neurexins isoforms (Tabuchi and Sudhof, 2002). The Nrxn proteins on axon terminals interact with postsynaptic NL proteins and have been shown to regulate synapse formation and function (Ichtchenko et al., 1995; Graf et al., 2004; Ko et al., 2009). NLs only bind to Nrxns, whereas Nrxns have large numbers of splice variants with differential binding affinities with multiple postsynaptic partners. Several key studies using a strategy of conditional Nrxns deletion in mice demonstrated that Nrxns regulate neurotransmission through different mechanisms in a cell-type specific manner (Chen et al., 2017; Luo et al., 2020; Luo et al., 2021). 
Despite the functional importance of DA in the brain, a limited number of studies have until now explored the molecular mechanisms underlying the unique nature of the axonal arbor and connectivity of DA neurons (Liu et al., 2018; Robinson et al., 2019; Banerjee et al., 2020; Banerjee et al., 2021; Delignat-Lavaud et al., 2021; Ducrot et al., 2021) and none examined the potential role of Nrxns in these neurons. Here we tested the hypothesis that Nrxns play a key role in regulating the connectivity and functions of DA neurons by deleting all Nrxns in these cells. We crossed DATIRES-Cre mice with Nrxn123 $\alpha / \beta$ floxed mice [Nrxn123 Triple conditional KO mice (Chen et al., 2017)]. We found that the density and the ultrastructure of synapses established by DA neurons were not affected. However, electrophysiological recordings showed an increase in GABA release from DA terminals in the ventral but nor dorsal striatum in $\mathrm{KO}$ mice, suggesting a region-specific negative regulatory role of Nrxns on GABA co-transmission. DA signaling was also altered after loss of Nrxns, as revealed by slower DA reuptake, decreased density of DA transporter (DAT), and increased density of vesicular monoamine transporter (VMAT2), accompanied by impaired amphetamine-induced locomotion.

\section{Results}

\section{Dopamine neuron survival and axonal connectivity are impaired by deletion of all Nrxns.}

Because Nrxns have been previously reported to influence the axonal development of neurons (Wang et al., 2019), we first examined the development of postnatal DA neurons in vitro as well as their basic connectivity. We deleted Nrxn 1,2 and 3 from DA neurons by crossing Nrxn123 flox/flox mice with DAT-IRES-Cre mice (DAT::NrxnsKO) and prepared primary co-cultures of SNc or VTA DA neurons together with ventral striatal neurons obtained from postnatal day 0-3 pups (P0-P3), as previously described (Ducrot et al., 2021). DA neurons were identified by TH immunocytochemistry and automated epifluorescence imaging (Fig. 1A). Intriguingly, the global survival of DA neurons in DAT::NrxnsKO cultures over 14 days was significantly reduced 
compared to WT controls (Fig. 1B) (two-way ANOVA, main effect of genotype; $\mathrm{F}(1,32)=5.00$, $p=0.032$ ). However, we did not detect any genotype or region-specific changes in neurite development, quantified as the number and length of TH-positive neurites (Fig. 1C and 1D).

A Automated scanning

Automated identification

Quantification
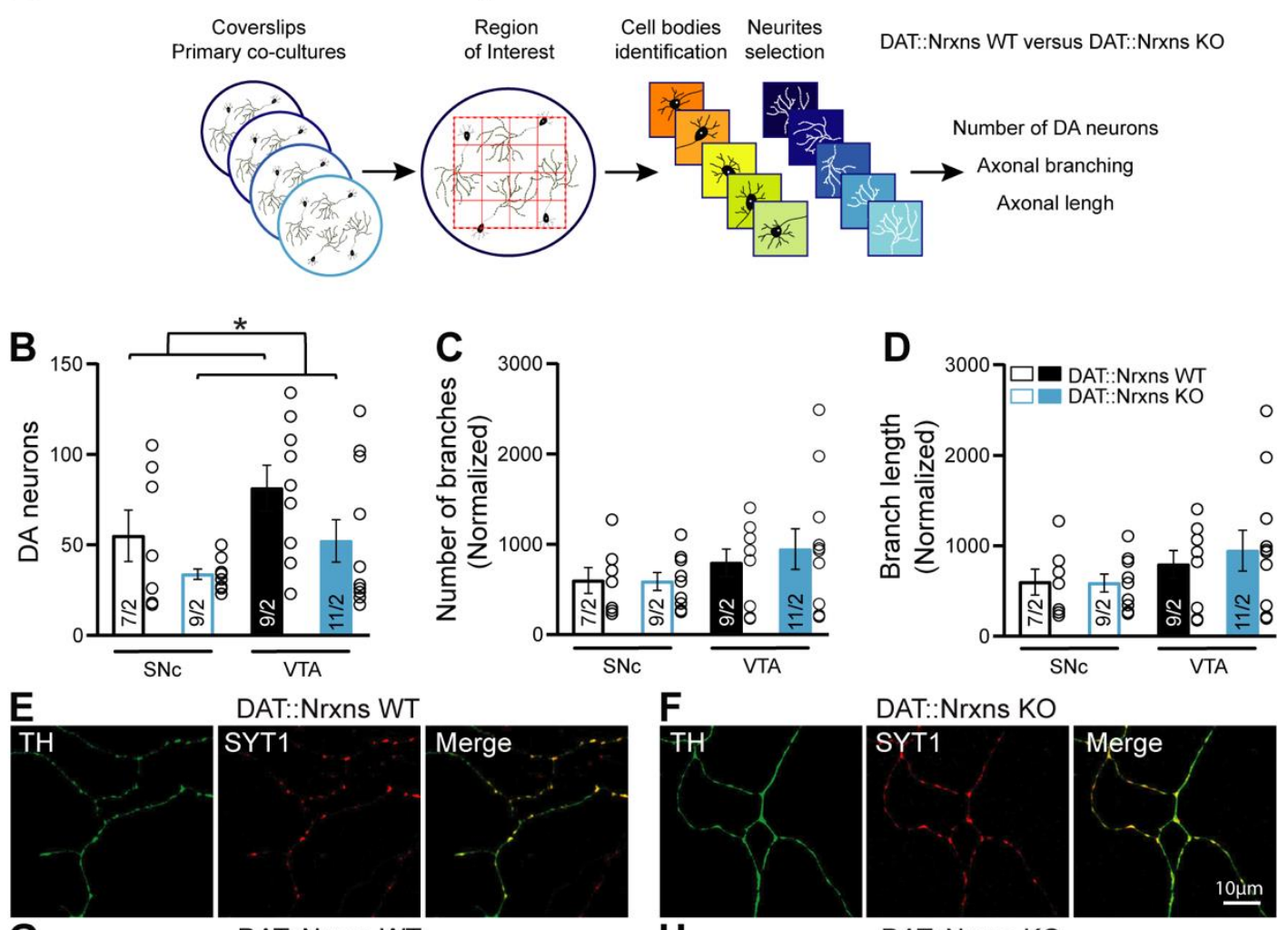

DAT::Nrxns WT
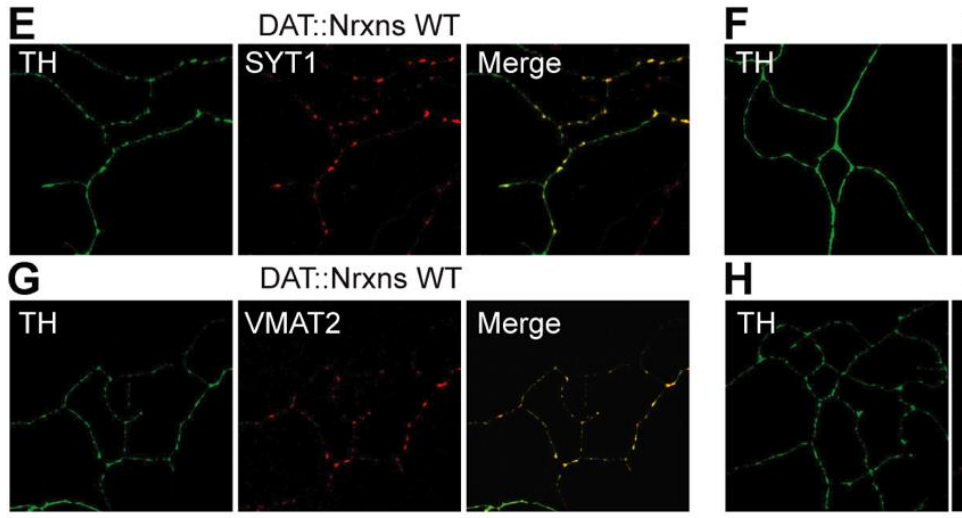

DAT::Nrxns KO

DAT::Nrxns WT
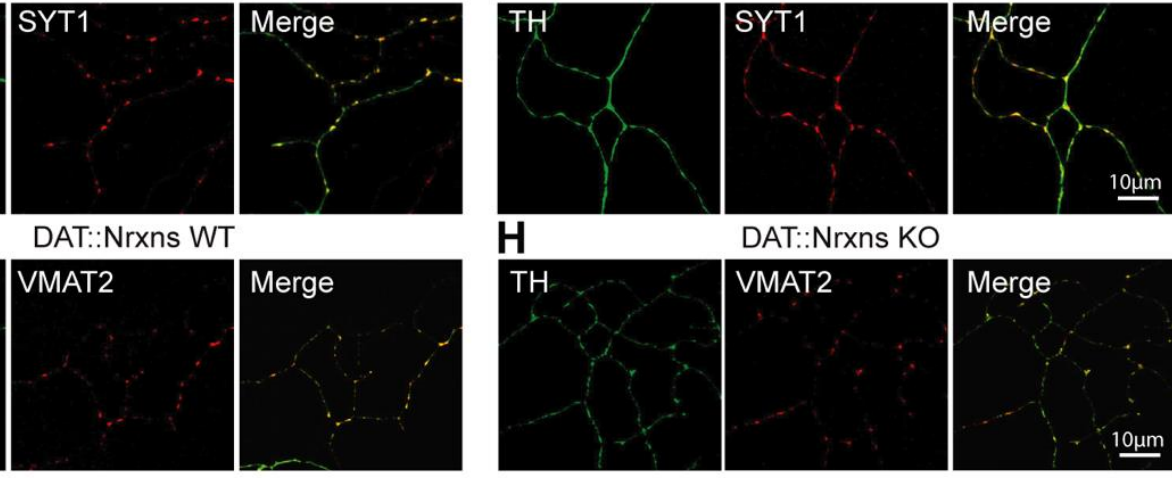

DAT::Nrxns KO
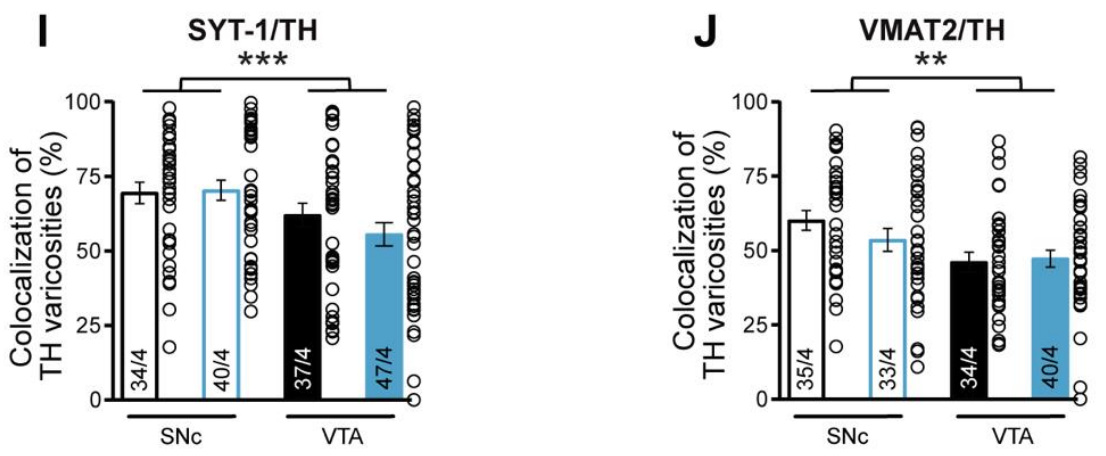
Figure 1 - Normal axonal growth in DA neurons after conditional deletion of all neurexins. A Illustration of the method used to evaluate and quantify the survival and growth of DA neurons lacking all neurexins. B - Quantification of DA neuron survival, assessed by their number per coverslip at 14DIV (SNc WT=55.00 \pm 14.18; SNc KO=33.78 \pm 2.84 ; VTA WT=81.33 \pm 12.62 ; VTA KO=52.18 \pm 11.72). C and D - Evaluation of neurite development in cultured DA neurons, assessed by quantifying the number of TH-positive processes (C) and their length (D) (Branch length: SNc WT=19086 \pm $1749 \mu \mathrm{m}$ versus $\mathrm{SNc} \mathrm{KO}=14950 \pm 2068 \mu \mathrm{m}$, VTA WT $=34721 \pm 9282 \mu \mathrm{m}$ versus $\mathrm{VTA} \mathrm{KO}=30593 \pm$ $4715 \mu \mathrm{m}$; Branch number: $\mathrm{SNc}$ WT= 598.9 \pm 143.3 versus $\mathrm{SNc} \mathrm{KO}=588.2 \pm 99.37$, VTA WT=795.4 \pm 152.6 versus VTA $\mathrm{KO}=945.7 \pm 225.7$ ). $\mathbf{E}$ and $\mathbf{F}$ - Photomicrographs illustrating the distribution of TH/Syt-1 positive axonal varicosities along the axonal domain of a SNc DA neuron from DAT::NrxnsWT and DAT::NrxnsKO mice (SNc WT=60.10 \pm 3.29 versus $\mathrm{SNc} \mathrm{KO}=53.58 \pm 3.81$; VTA $\mathrm{WT}=46.11 \pm 3.34$ versus $\mathrm{VTA} \mathrm{KO}=47.30 \pm 2.86$. G and $\mathbf{H}$ - Photomicrographs illustrating the distribution of TH/VMAT2 positive axonal varicosities along the axonal domain of a SNc DA neuron from DAT::NrxnsWT and DAT::NrxnsKO mice. I- Summary graph showing the proportion of THpositive terminals containing Syt1. J-Summary graph showing the proportion of TH-positive terminals containing VMAT2. For axonal growth assessment: $n=7-11$ coverslips from 2 different neuronal cocultures. For Syt1/VMAT2 quantifications: $n=33-44$ axonal fields from 4 different neuronal co-cultures. The number of observations represent the number of fields from individual neurons examined. For all analyses, the plots represent the mean \pm SEM. Statistical analysis was carried out by two-way ANOVAs followed by Šidák's corrections (*p $<0.05$; **p $<0.01$; ***p $<0.001$; ****p $<0.0001)$.

In a second set of analyses, we also examined some of the characteristics of axon terminals established by DAT::NrxnsKO and DAT::NrxnsWT DA neurons (Fig. 1E to 1H). After doublelabelling for TH and for Syt1, the ubiquitous exocytosis $\mathrm{Ca}^{2+}$ sensor, fields containing axonal arbors were examined for colocalization analysis. Our results show that the proportion of dopaminergic varicosities containing Syt1 was significantly lower in VTA DA neurons compared to SNc DA neurons as previously observed (Ducrot et al., 2021) (Fig. 1E, 1F, 1I; two-way ANOVA, main effect of region; $\mathrm{F}(1,143)=13.83, p=0.0003)$, with no effect of genotype. Similarly, double labelling for VMAT2, the transporter responsible for vesicular packaging of DA, showed that the proportion of dopaminergic varicosities containing VMAT2 was significantly lower for VTA neurons compared to SNc neurons (Fig. 1G, 1H, 1J; two-way ANOVA, main effect of region (F(1, 138)=9.33, $p=0.0027$ ), with no effect of genotype. We conclude that, although loss of Nrxns may decrease the resilience of DA neurons, it does not alter the intrinsic capacity of these neurons to develop an axonal domain and to establish neurotransmitter release sites. 
A subset of terminals along the complex axonal arbor of DA neurons has the capacity to release glutamate or GABA (Sulzer et al., 1998; Dal Bo et al., 2004; Mendez et al., 2008; Stuber et al., 2010; Tritsch et al., 2012; Tritsch et al., 2016). We hypothesized that deletion of Nrxns could alter the formation of excitatory or inhibitory synapses by SNc and VTA DA neurons. To test this, we co-cultured DA neurons with striatal neurons, and examined dopaminergic axon terminals in close proximity to postsynaptic organizers associated with glutamate (PSD95) and GABA (gephyrin) synapses (Craig et al., 1996; Kornau et al., 1997). We observed that loss of Nrxns reduced the proportion of SNc, but not VTA, DA neuron terminals colocalized with PSD95 (Fig. 2A, 2B, 2C; two-way ANOVA, main effect of region, $\mathrm{F}(1,139)=7.65, p=0.0065$; Sidak's multiple comparison test, SNc WT vs SNc KO DA neurons, $p=0.035)$. We also detected a significant decrease of the proportion of SNc DA neuron terminals colocalizing with gephyrin (Fig. 2D; twoway ANOVA, $\mathrm{F}(1,115)=4.53 ; p=0.035$; Sidak's multiple comparison test, SNc WT vs SNc KO DA neurons, $p=0.04)$. No change was observed for VTA DA neurons. In previous work, we showed that most bassoon-positive DA neuron terminals are near target cells and most likely to be found at synapses (Ducrot et al., 2021). Thus, we evaluated the proportion of DA neuron terminals expressing the glutamatergic active zone protein bassoon. We found a significant decrease in the proportion of SNc DA terminals that were bassoon positive (Fig. 2E; two-way ANOVA, main effect of region, $\mathrm{F}(1,163)=5.42, p=0.021$, and globally, there was a reduced proportion of terminals that were bassoon positive in KO DA neurons (main effect of genotype, $\mathrm{F}(1,163)=4.32$, $p=0.039$ ). This effect was selective for SNc DA neurons as no difference was found for VTA DA neurons (Fig. 2E; Sidak's multiple comparison test, SNc WT vs SNc KO DA neurons, $p=0.049$ ). We conclude that these transsynaptic proteins regulate synaptic organization in a region-specific manner, compatible with previous results (Luo et al., 2020). 


\section{SNc DA neurons}
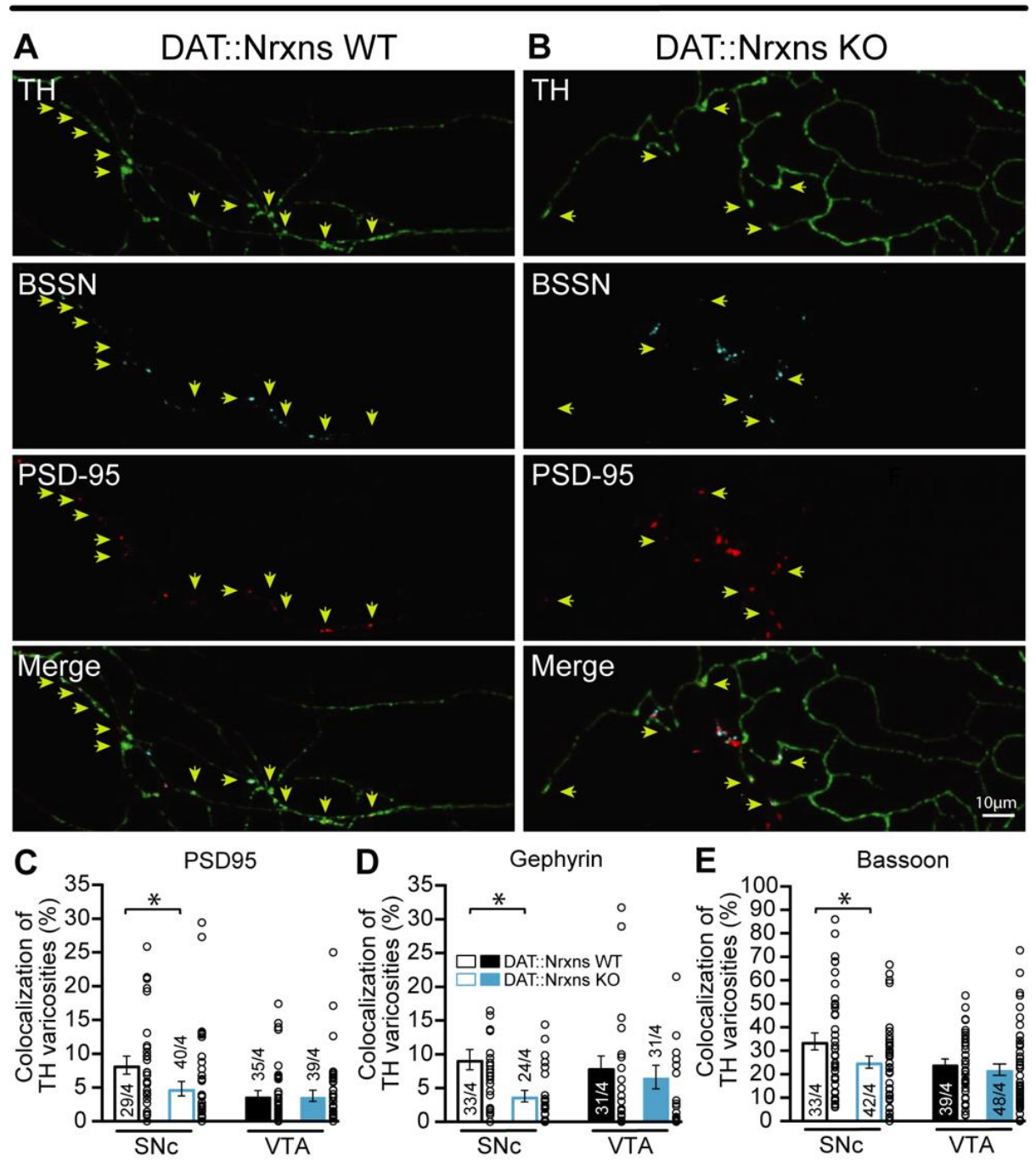

Figure 2 - The proportion of synapses established by cultured SNc DA neurons is reduced after conditional deletion of all neurexins. A and B- Representative images illustrating TH-positive varicosities in the axonal arbor of a SNc DA neuron from DAT::NrxnsWT and DAT::NrxnsKO mice. Bassoon was expressed sparsely and colocalized with the postsynaptic marker PSD95. C- Bar graph representing the proportion (\%) of axonal varicosities established by VTA and SNc DA neurons that are positive for TH and colocalizing with PSD95 at 14 DIV (SNc WT $8.32 \pm 1.32 \%$ versus SNc KO $4.82 \pm 1.08 \%$ and VTA WT $3.78 \pm 0.78 \%$; VTA KO $3.78 \pm 0.81 \%)$. D- Bar graph representing the proportion (\%) of axonal varicosities established by VTA and SNc DA neurons that are positive for $\mathrm{TH}$ and colocalizing with gephyrin at $14 \mathrm{DIV}$ (SNc WT 9.22 $\pm 1.50 \%$ versus SNc KO $3.80 \pm 0.83 \%$ and VTA WT $7.99 \pm 1.76 \%$ versus VTA KO $6.64 \pm 1.75 \%$ ). E - Bar graph representing the proportion (\%) of axonal varicosities that are positive for bassoon in VTA and SNc DA neurons from DAT::NrxnsWT and DAT::NrxnsKO mice (SNc WT $33.98 \pm 3.62 \%$ versus SNc KO 25.09 $\pm 2.57 \%$ and VTA WT $24.42 \pm 2.13 \%$ versus VTA KO $21.97 \pm 2.43 \%$ ). Data represent mean \pm SEM. Statistical analyses were performed by two-tailed Student's T-tests $(* \mathrm{p}<0.05 ; * * \mathrm{p}<0.01 ; * * * \mathrm{p}<0.001)$. 


\section{Nrxn123 ablation does not impair synapse ultrastructure in dopamine neurons.}

We next examined synaptic ultrastructure in the intact brain by transmission electron microscopy (TEM) to directly test our hypothesis that Nrxns regulate the integrity of synapses established by DA neurons. We focused on terminals in the vSTR because this area contains DA neuron release sites for both glutamate and GABA in addition to those for DA (Stuber et al., 2010; Berube-Carriere et al., 2012). Overall, we found that, irrespective of the genotype, most axonal varicosities contained synaptic vesicles and mitochondria (Fig. 3A and 3B). Furthermore, THpositive dopaminergic terminals in the vSTR of Nrxn123 KO were not different compared to Nrxn123 WT mice in terms of their overall perimeters (P) (Fig. 3D; unpaired t-test, $\mathrm{t}_{6}=0.07$; $p=0.94$ ), length (L) (Fig. 3E, unpaired t-test, $\left.\mathrm{t}_{6}=0.72 ; p=0.94\right)$, width (w) (Fig. 3F, unpaired t-test, $\left.\mathrm{t}_{6}=0.84 ; p=0.43\right)$, or surface area (Fig. 3G, unpaired t-test, $\left.\mathrm{t}_{6}=0.09, p=0.92\right)$.

In addition, the propensity of these terminals to make contact with a postsynaptic density (PSD) domain was unchanged in DAT::NrxnsKO mice. The synaptic incidence of TH-positive terminals was $6.34 \%$ (12/189 examined varicosities) for DAT::NrxnsKO mice and 4.95\% (5/101 examined varicosities) for control mice (not shown), a low proportion in line with previous work (Stuber et al., 2010; Berube-Carriere et al., 2012). The size of the PSD was also unchanged (Fig. 3H, unpaired t-test, $\left.\mathrm{t}_{15}=0.61, p=0.54\right)$. Together, these results show that loss of Nrxns123 does not impair the basic ultrastructure of DA neuron neurotransmitter release sites in the vSTR. 

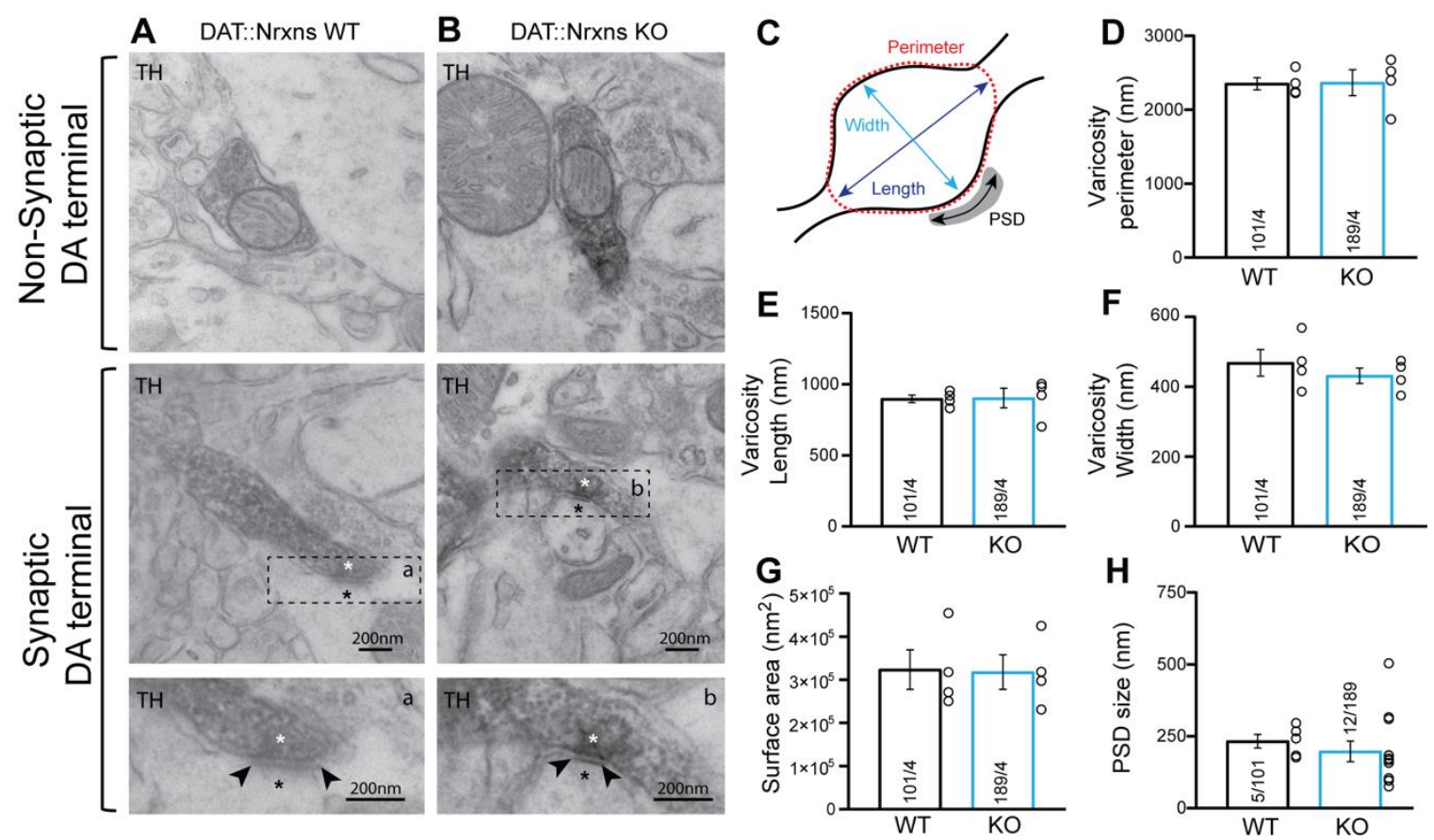

Figure 3 - Synaptic and non-synaptic ultrastructure of DA terminals is unchanged after Nrxn123 triple knockout in dopamine neurons. A-B Electron micrographs showing DA neuron terminals without any PSD domain (top images) or in apposition to a PSD domain in ventral striatal tissue from DAT::NrxnsWT and KO mice. The lower micrograph represents a magnified view of the regions identified by the doted lines in the middle images. The asterisk identifies a synapse and the black arrowheads delimitate the postsynaptic domain. C- Schematic representation of a dopaminergic varicosity. D- Bar graph representing the perimeter of the DA axonal varicosity from WT and KO mice $(2227 \pm 81.83 \mathrm{~nm}$ and $1870 \pm 174.8 \mathrm{~nm}$, respectively), $\mathbf{E}$ and $\mathbf{F}$ - Bar graphs representing the size of the axonal varicosities, quantified as length $(\mathbf{E})(897.3 \pm 38.06 \mathrm{~nm}$ and $902.7 \pm 38.06 \mathrm{~nm}$ respectively $)$ and width (F) $(468.7 \pm 38.06 \mathrm{~nm}$ and $375.2 \pm 22.02 \mathrm{~nm}$, respectively). G- Bar graphs showing the surface area of DA neuron varicosities from WT and KO animals $\left(323537 \pm 45861 \mathrm{~nm}^{2}\right.$ and $317887 \pm 40227 \mathrm{~nm}^{2}$, respectively). H- Bar graphs representing the PSD domain size $(232.8 \pm 23.40 \mathrm{~nm}$ and $197.1 \pm 35.71 \mathrm{~nm}$, respectively for WT and KO mice). For all analyses, WT=101 and $\mathrm{KO}=189$ axonal varicosities from 4 different mice for each genotype. For all analyses, plots represent the mean \pm SEM. Statistical analyses were carried out by unpaired t-tests $\left(* \mathrm{p}<0.05 ; * *^{*} \mathrm{p}<0.01 ; * * \mathrm{p}<0.001 ; * * * \mathrm{p}<0.0001\right)$.

\section{Deletion of Nrxns reduces amphetamine-induced locomotion without affecting basal motor}

\section{activity or coordination.}

Although we did not observe an overall structural change in DA neuron terminals in Nrxn123KO mice, a region-specific change in both excitatory and inhibitory synaptic connections established by DA neurons was detected. Because DA neurons are key regulators of movement, 
motivation, and reward-dependent learning and several studies using mouse lines with impaired DA transmission reported deficits in basal or psychostimulant-evoked locomotion and learning on the accelerating rotarod (Zhou and Palmiter, 1995; Ogura et al., 2005; Birgner et al., 2010), we therefore examined DA-dependent behaviors in Nrxn123 KO mice. In the first series of experiment, we evaluated motor coordination and learning using the accelerating rotarod task with two different protocols (Fig. 4A). The first protocol evaluated the rate of learning to perform this task over a total of 9 sessions during 3 days, with two sessions performed on the first day, three sessions the second day, and four sessions on the third day, with a speed of rotation accelerating from 4 to $40 \mathrm{rpm}$ over $10 \mathrm{~min}$. The measure of latency to fall did not reveal a significant difference between the genotypes, with all groups showing a comparable increase in performance (Fig. 4B, two-way repeated measures ANOVA, $\mathrm{F}(2,22)=1.59, p=0.22)$. Similar results were obtained when evaluating the progression of the performance of the mice by comparing the first and last sessions, with all mice showing equivalent learning (Fig. 4C; two-way ANOVA, main effect of training session, F(1, 22) $=48.71, p<0.0001$; Sidak's multiple comparisons test, S1 vs S9 : WT, $p=0.022$; HET, $p=0.0002$; $\mathrm{KO}, p=0.001$; no genotype effect was observed). The speed of rotation at the end of each trial across all 9 trials was also unchanged (Fig. 4D; two-way repeated measures $\operatorname{ANOVA,~F(2,~22)=1.52,~}$ $p=0.24)$. Furthermore, testing a separate cohort of mice with a more challenging version of the rotarod task (Fig. 4A), with speed of rotation accelerating from 4 to $40 \mathrm{rpm}$ over $2 \mathrm{~min}$, revealed that performance, calculated by the latency to fall, was not significantly different in DAT::NrxnsKO and DAT::NrxnsHET compared to DAT::NrxnsWT (Fig. 4E, two-way ANOVA, repeated measures, $\mathrm{F}(2,29)=2.81, p=0.07)$. In this task, performance failed to improve over the trials, revealing a limited capacity to improve performance, as shown by comparing performance in the last session compared to the first (Fig. 4F; two-way ANOVA, $\mathrm{F}(1,29)=0.097, p=0.75)$. The speed of rotation at the end of each trial across all 9 trials (Fig. 4G) was similar in DAT::NrxnsKO mice compared to the control mice (two-way repeated measures ANOVA, $\mathrm{F}(2,29)=2.54, p=0.09)$. 
bioRxiv preprint doi: https://doi.org/10.1101/2021.10.17.464666; this version posted November 26, 2021. The copyright holder for this preprint (which was not certified by peer review) is the author/funder, who has granted bioRxiv a license to display the preprint in perpetuity. It is made available under aCC-BY 4.0 International license.

These results suggest that deletion of Nrxn123 from DA neurons do not lead to motor coordination deficits.

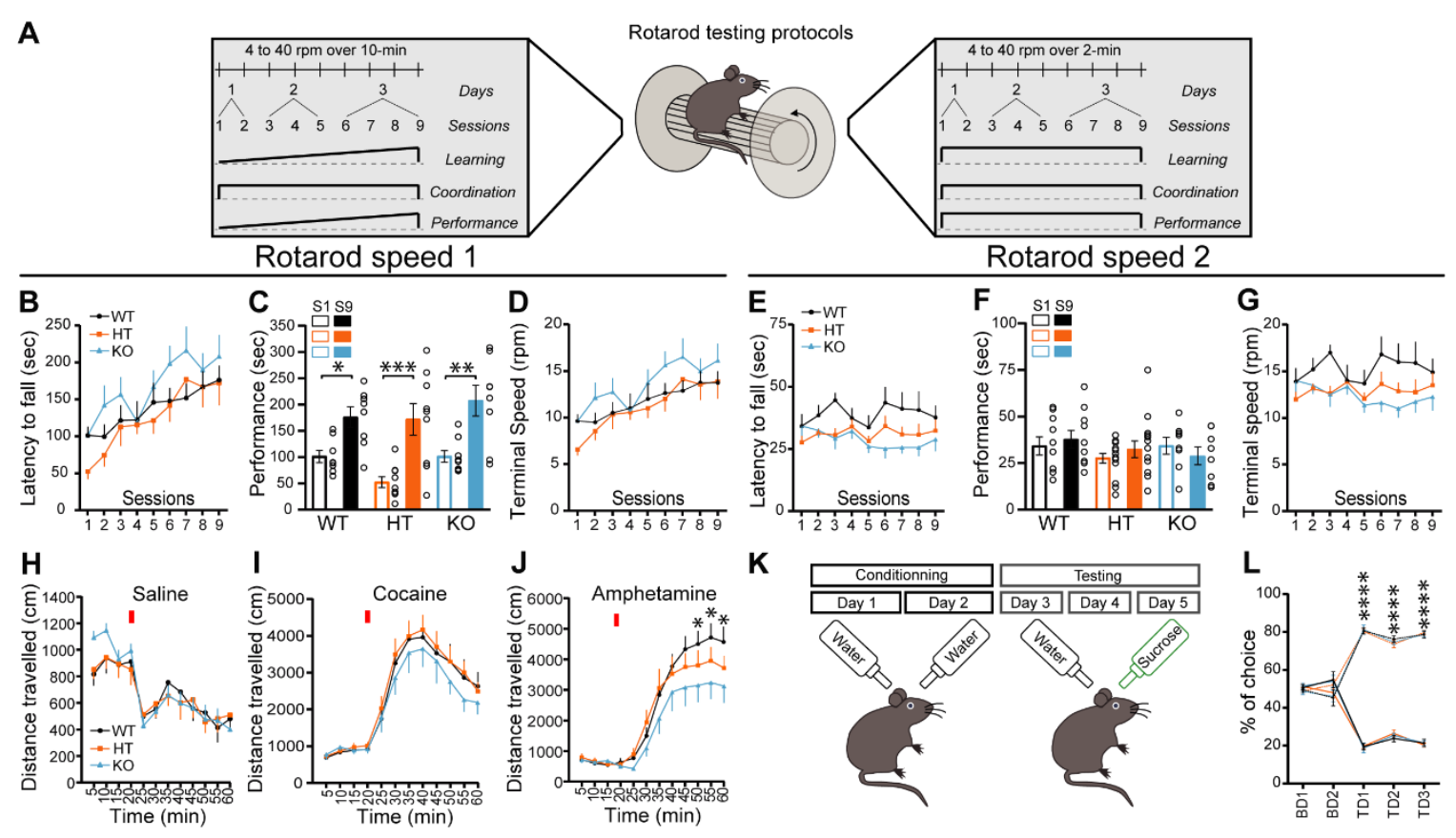


Figure 4 - DAT::NrxnsKO mice exhibit impaired amphetamine-induced motor activity. ASchematic representation of a mouse on a rotarod and the diagram of the two rotarod testing protocols. BPerformance on the accelerating rotarod during 9 sessions over 3 consecutive days. Latency to fall was quantified at rotation speeds from 4 to $40 \mathrm{rpm}$ over $10 \mathrm{~min}$. C- Performance of DAT::NrxnsKO, HET and WT littermate mice on the rotarod were evaluated comparing the last session and the first session for each mouse. The results show a significant improvement in performance irrespective of genotype. DQuantification of the terminal speed over all the sessions shows no difference between the DAT::NrxnsKO, HET and WT littermate mice. E- Performance on the second accelerating rotarod task during 9 sessions over 3 consecutive days. Latency to fall was quantified at rotation speeds from 4 to 40 rpm over 2-min. F- Performance of DAT::NrxnsWT, HET and KO littermate mice on the rotarod was evaluated comparing the last and first sessions for each mouse. No significant improvement in performance was detected, irrespective of genotype. G- Quantification of the final speed over all sessions shows no difference between the DAT::NrxnsWT, HET and KO littermate mice. H- Basal horizontal activity in a novel environment before and after a saline injection $(10 \mathrm{ml} / \mathrm{kg})$ over a total of $60-\mathrm{min}$. IHorizontal activity before and after a cocaine injection $(20 \mathrm{mg} / \mathrm{kg} ; 10 \mathrm{ml} / \mathrm{kg})$ over a total of $60-\mathrm{min}$. JHorizontal activity before and after an amphetamine injection $(5 \mathrm{mg} / \mathrm{kg} ; 10 \mathrm{ml} / \mathrm{kg}$ ) over $60-\mathrm{min}$, shows reduced locomotion in the DAT::NrxnsKO compared to the control mice. K-Schematic representation of the sucrose preference testing protocol. L- Quantification of sucrose preference in comparison to water consumption represented as a percentage. Initial two days: DAT::NrxnsKO CD1: $51.47 \pm 1.63 \%$ vs 48.52 $\pm 1.63 \%$ and CD2: $54.01 \pm 3.17 \%$, vs $45.99 \pm 3.17 \%$; DAT::NrxnsHET CD1: $51.16 \pm 1.81 \%$ vs $48.83 \pm$ $1.81 \%$ and CD2: $47.90 \pm 2.74 \%$, vs $52.09 \pm 2.74 \%$; DAT::NrxnsWT CD1: $50.58 \pm 1.47 \%$ vs $49.41 \pm$ $1.47 \%$ and CD2: $54.73 \pm 4.27 \%$, vs $45.26 \pm 4.27 \%$. Results are presented as percentage of choice water/water. Following three test days: DAT::NrxnsKO TD1: $81.24 \pm 2.44 \%$ vs $18.75 \pm 2.44 \%$; TD2: $74.65 \pm 1.39 \%$, vs $25.34 \pm 1.39 \%$ and TD3: $78.74 \pm 1.37 \%$, vs $21.25 \pm 1.37 \%$; DAT::NrxnsHET TD1: $80.30 \pm 1.39 \%$ vs $19.69 \pm 1.39 \%$; TD2: $73.57 \pm 1.85 \%$, vs $26.43 \pm 1.85 \%$ and TD3: $79.68 \pm 0.96 \%$ vs $20.32 \pm 0.96 \%$; DAT::NrxnsWT TD1: $80.52 \pm 1.74 \%$ vs $19.47 \pm 1.74 \%$; TD2: $76.21 \pm 1.75 \%$, vs 23.78 $\pm 1.75 \%$ and TD3: $78.58 \pm 2.00 \%$, vs $21.41 \pm 2.00 \%$ ). Results are presented as percentage of choice water/water. Following three test days: DAT::NrxnsKO TD1: $81.24 \pm 2.44 \%$ vs $18.75 \pm 2.44 \%$; TD2: $74.65 \pm 1.39 \%$, vs $25.34 \pm 1.39 \%$ and TD $3: 78.74 \pm 1.37 \%$, vs $21.25 \pm 1.37 \%$; DAT::NrxnsHET TD1: $80.30 \pm 1.39 \%$ vs $19.69 \pm 1.39 \%$; TD2: $73.57 \pm 1.85 \%$, vs $26.43 \pm 1.85 \%$ and TD $3: 79.68 \pm 0.96 \%$ vs $20.32 \pm 0.96 \%$; DAT::NrxnsWT TD1: $80.52 \pm 1.74 \%$ vs $19.47 \pm 1.74 \%$; TD2: $76.21 \pm 1.75 \%$, vs 23.78 $\pm 1.75 \%$ and TD3: $78.58 \pm 2.00 \%$, vs $21.41 \pm 2.00 \%$ ). All results are presented as percentage of choice sucrose/water. For rotarod and locomotor activity experiments, 7 to 14 animals per group were used. For sucrose experiment, 7 to 86 mice per group were used). For all analyses, the plots represent the mean \pm

General motor abilities were next evaluated using the pole test and the open field test. In the pole test (Fig. S1A), no difference was observed between genotypes for the time required for the mice to orient downward (Fig. S1B) (one-way ANOVA, F(2; 25)=0.92, $p=0.4$ ) and for the time required to climb down the pole (Fig. S1C) (one-way ANOVA, $\mathrm{F}(2 ; 25)=2.8, p=0.08$ ). Basal locomotion in the open field over a 60-min period was also not different between genotypes (Fig. 4H; two-way ANOVA, $\mathrm{F}(2 ; 28)=0.95, p=0.95)$. We next challenged the dopaminergic system of these mice using the psychostimulants cocaine and amphetamine (Di Chiara and Imperato, 1988). 
Although locomotion induced by cocaine $(5 \mathrm{mg} / \mathrm{kg})$ was comparable between genotypes (Fig. 4I, two-way ANOVA, $\mathrm{F}(2 ; 26)=0.36, p=0.67)$, locomotion induced in response to amphetamine was strongly reduced in DAT::NrxnsKO mice compared to DAT::NrxnsHET and DAT::NrxnsWT mice (Fig. 4J, two-way ANOVA, main effect of time; $\mathrm{F}(11 ; 228)=45.95$ and genotype $\mathrm{F}(2,228)=9.67$, $p<0.0001$ ). The maximal effect was observed between 30 to 40 min post-injection (Fig. 4J; twoway ANOVA, Tukey's multiple comparisons test, DAT::NrxnsKO vs WT. $\mathrm{t}=50 \mathrm{~min}: p=0.03$; $\mathrm{t}=55 \min : p=0.01 ; \mathrm{t}=60 \mathrm{~min}: p=0.02)$. These results suggest that loss of Nrxns in DA neurons leads to altered DA neurotransmission and DA-dependent behaviors.

Because altered DA neurotransmission is often associated with changes in states of motivation, we next examined the performance of the mice in a well-established sucrose preference task. On the initial two conditioning days (CD1 and CD2), mice of all genotypes equally licked at both bottles (Fig. 4K, 4L). Similarly, during the next 3 testing days (TD1, 2 and 3), when mice were given a choice between water and sucrose, DAT::NrxnsKO, HET and WT mice showed a similar marked preference for the sucrose bottle (Fig. 4L; two-way ANOVA, main effect of choice $\mathrm{F}(5 ; 40)=498.0$; Tukey's multiple comparisons test, Test Day 1, 2, 3, water versus sucrose, all genotypes, $p<0.0001)$. These findings suggest that the response of DAT::NrxnKO mice to natural rewards was unaltered.

\section{Fast Scan Cyclic Voltammetry reveals normal DA release but slower reuptake and enhanced paired-pulse depression after conditional deletion of all Nrxns in DA neurons.}

The impaired response to amphetamine suggests a perturbation of extracellular DA dynamics or DA action on target cells. To examine this possibility, we first employed fast scan cyclic voltammetry (FSCV) to measure electrically-evoked DA overflow in acute brain slices of the ventral and dorsal striatum (vSTR and dSTR). In the dSTR, we found no difference in peak DA overflow between the DAT::NrxnsWT and DAT::NrxnsKO mice, but surprisingly, in the 
DAT::NrxnsHET mice, peak DA overflow was significantly lower (One-way ANOVA, F(2; 179)=7.06, $p=0.001$, Tukey's multiple comparisons test, WT vs HET, $p=0.002$ and HET vs KO, $p=0.006)$ compared to the WT and KO mice (Fig. 5A and 5B).

An examination of the kinetics of DA overflow is often used to identify changes in DA release efficiency and reuptake (Yorgason et al., 2011). We found that DA reuptake in the dSTR was significantly slower in DAT::NrxnsKO and DAT::NrxnsHET compared to DAT::NrxnsWT mice (One-way ANOVA, main effect of genotype, $\mathrm{F}(2,140)=5.82, p=0.0037$ ), as illustrated by higher Tau values (Fig. 5A and 5C; Tukey's multiple comparisons test; WT vs KO $p=0.034$; WT vs HET $p=0.041$ ). We also observed a similar increase in Tau for DA reuptake in the vSTR (Fig. 5E and 5G; One-way ANOVA, main effect of genotype, $\mathrm{F}(2,137)=12.17, p<0.0001$; Tukey's multiple comparisons test; WT vs KO $p=0.017$; WT vs HET $p<0.0001)$. 


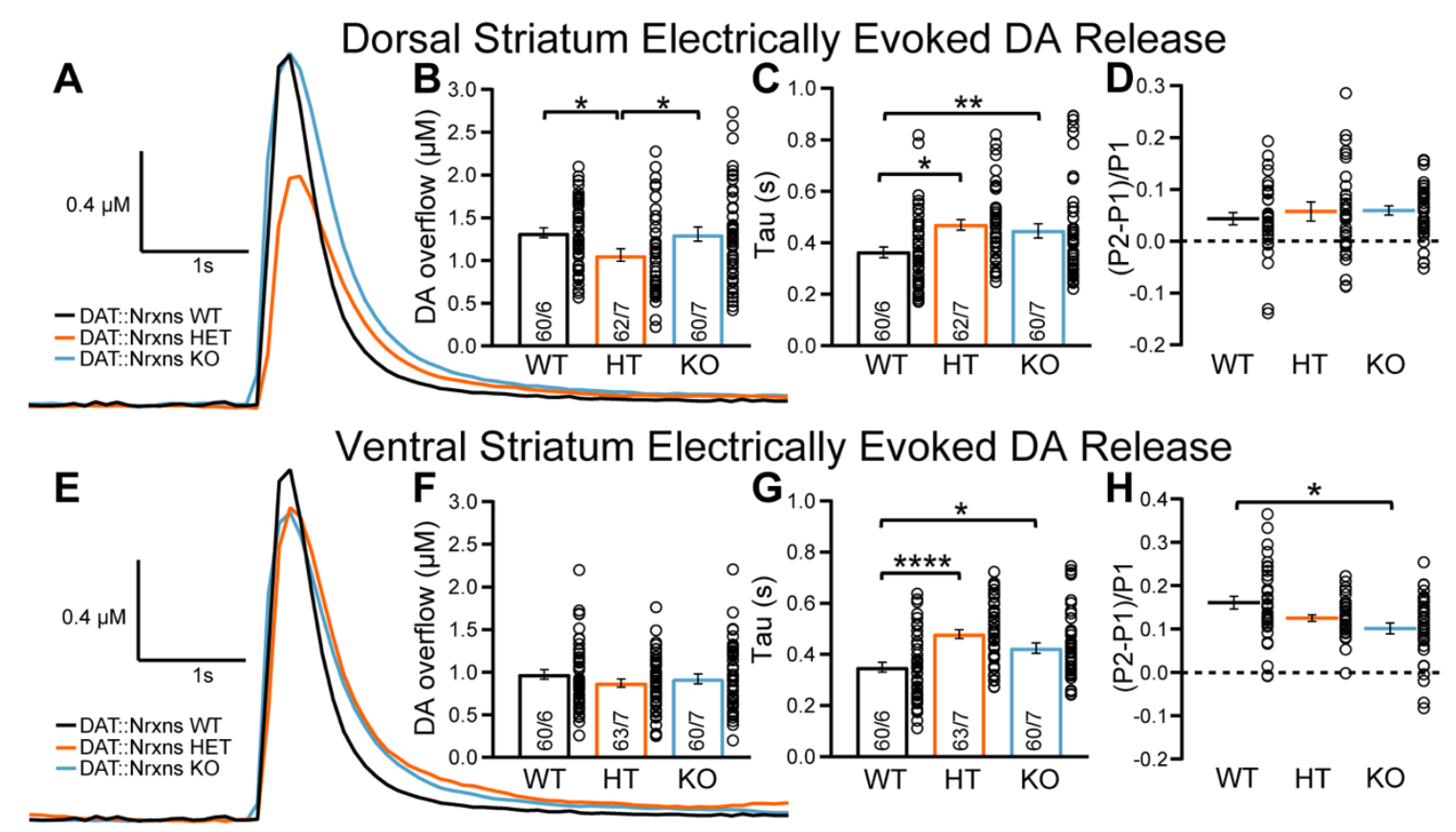

Figure 5 - Slower dopamine reuptake in DAT::NrxnsKO mice. A- Representative traces of electrically evoked DA levels detected by fast-scan cyclic voltammetry in the dorsal striatum, measured in slices prepared from DAT::NrxnsWT, HET and KO mice. B- Bar graphs showing the average DA levels $(\mu \mathrm{M})$ detected in the dorsal striatum $(\mathrm{WT}=1.33 \pm 0.05 \mu \mathrm{M}$; HET $=1.05 \pm 0.05 \mu \mathrm{M}$ and $\mathrm{KO}=1.35 \pm 0.07 \mu \mathrm{M})$. CEvaluation of DA release kinetics in the dorsal striatum estimated by quantifying Tau, corresponding to reuptake efficiency $(\mathrm{WT}=0.36 \pm 0.02 \mathrm{~s} ; \mathrm{HET}=0.47 \pm 0.02 \mathrm{~s}$ and $\mathrm{KO}=0.45 \pm 0.03 \mathrm{~s})$. D- Short-term pairedpulse induced plasticity of DA overflow in dorsal striatal slices, estimated by calculating (P2-P1/P1) with an inter-pulse interval of $100 \mathrm{~ms}$. The low ratio values reflect the strong paired-pulse depression seen at such release sites in acute brain slices. E- Representative traces of electrically evoked DA levels detected by fast-scan cyclic voltammetry in the ventral striatum. F- Bar graphs showing the average of DA levels $(\mu \mathrm{M})$ detected in the ventral striatum $(\mathrm{WT}=0.98 \pm 0.04 \mu \mathrm{M} ; \mathrm{HET}=0.88 \pm 0.05 \mu \mathrm{M}$ and $\mathrm{KO}=0.98 \pm$ $0.06 \mu \mathrm{M})$. G- Evaluation of DA release kinetics in the ventral striatum, estimated by quantifying Tau $(\mathrm{WT}=0.35 \pm 0.02 ; \mathrm{HET}=0.47 \pm 0.02$ and $\mathrm{KO}=0.42 \pm 0.02)$. H- Short-term paired-pulse induced plasticity of DA overflow in ventral striatal slices, estimated by calculating (P2-P1/P1) with an inter-pulse interval at $100-\mathrm{ms}$. The low ratio values reflect the strong paired-pulse depression seen at such release sites in acute brain slices. Data are presented as mean \pm SEM. Statistical analyses were performed with a one-way ANOVA $(* \mathrm{p}<0.05 ; * * \mathrm{p}<0.01 ; * * * \mathrm{p}<0.001)$

Quantification of the rise-time of evoked DA overflow in the dSTR revealed a slower rise time in DAT::NrxnsHET mice compared to DAT::NrxnsWT mice (Fig. S2A; One-way ANOVA, main effect of genotype, $\mathrm{F}(2,141)=3.23, p=0.42$, Holm-Šidák's multiple comparisons test, HET vs WT, $p=0.044)$. No differences were found in the vSTR (Fig. S2B). 
Short-term plasticity of electrically evoked DA release in the striatum was examined using a paired-pulse stimulation paradigm. DA overflow in acute brain slices typically shows a large paired-pulse depression, more extensively so in the dSTR compared to the vSTR (Zhang and Sulzer, 2004; Sanchez et al., 2014; Condon et al., 2019). We found a significant difference that was selective for the vSTR. Indeed, the level of paired-pulse depression was similar in DAT::NrxnsKO mice compared to WT in the dSTR (Fig. 5D; One-way ANOVA; F(2, 107)=0.36, $p=0.69$ ). However, in the vSTR, paired-pulse depression was significantly enhanced in DAT::NrxnsKO mice compared to WT (Fig. 5H; One-way ANOVA; F(2, 103)=4.88, $p=0.0094$; Tukey's multiple comparison test, $p=0.0082$ ). Plasticity of DA release was also examined by measuring the inhibition of DA overflow induced by the GABA $\mathrm{B}_{\mathrm{B}}$ agonist baclofen $(10 \mu \mathrm{M})$ (Lopes et al., 2019). A recent study demonstrated a role for Nrxns in the regulation of the expression and location of presynaptic $\mathrm{GABA}_{\mathrm{B}}$ receptors in glutamatergic and GABAergic neurons (Luo et al., 2021). Our results show that baclofen-induced inhibition of DA overflow was not different across genotypes (Fig. S1C; Two-way ANOVA, $\mathrm{F}(1,12)=0.008, p=0.93)$.

Together these observations suggest that Nrxns, while not required for DA release, play a role in regulating DA neurotransmission through regulation of DA reuptake and short-term plasticity in the vSTR. Our results suggest that Nrxns regulate DA release by means other than regulation of presynaptic $\mathrm{GABA}_{\mathrm{B}}$ receptors.

\section{GABA release by dopamine neurons is increased in the ventral striatum of DAT::NrxnsKO}

mice.

Whole-cell patch-clamp recordings in medium spiny neurons (MSNs) of the vSTR and dSTR in DAT::NrxnsWT, HET and KO littermates were performed to examine the role of Nrxns in synaptic GABA and glutamate release by DA neurons. A conditional AAV construct containing ChR2-EYFP was injected in the ventral mesencephalon and infected most of the neurons in the 
VTA and SNc of DAT-Cre::Nrxn mice (Fig. 6A, 6B). We isolated GABA-mediated synaptic currents (IPSC) pharmacologically and found a significant increase in the amplitude of IPSCs evoked by optical stimulation of DA neurons axons (oIPSCs) in the DAT::NrxnsKO slices (Fig. 6C; One-way ANOVA, $\mathrm{F}(2,30)=6.46, p=0.005)$, with no change in electrically evoked GABA synaptic currents (eIPSC; Fig. S3A; One-way ANOVA, F(2, 35) = 1.46, $p=0.24$ ). Interestingly, the frequency of spontaneous IPSCs (sIPSCs) was also significantly increased in the KO group (Fig. 6D; One-way ANOVA, F(2, 37) = 3.7, $p=0.03$ ). oIPSCs were blocked by picrotoxin (50 $\mu \mathrm{M}$ ), confirming their GABAergic nature (Fig. S4A). Furthermore, oIPSCs were blocked after treatment with the VMAT2 inhibitor reserpine $(1 \mu \mathrm{M})$, in line with previous work showing that GABA release by DA neurons paradoxically requires VMAT2 (Tritsch et al., 2012; Tritsch et al., 2014) (Fig. S4C).

A
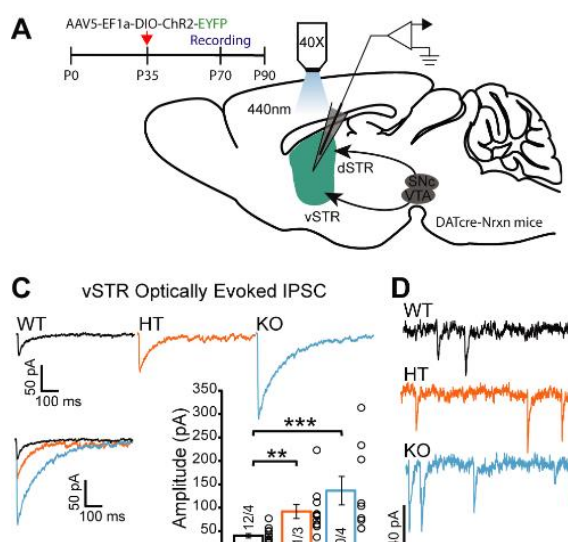

Optically Evoked IPSC HT KO

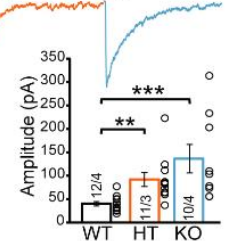

F dSTR Optically Evoked IPSC

高

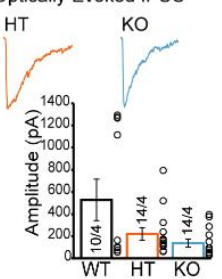

D

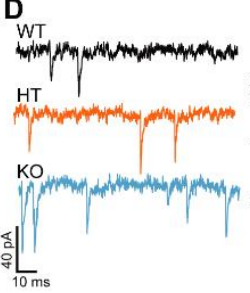

G WT

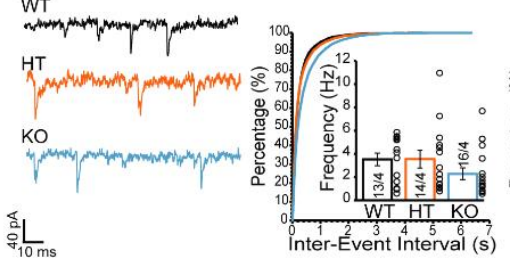

vSTR Spontaneous IPSC

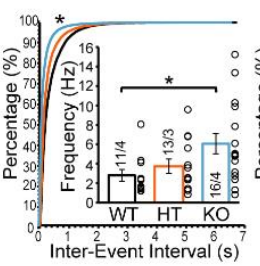

dSTR Spontaneous IPSC
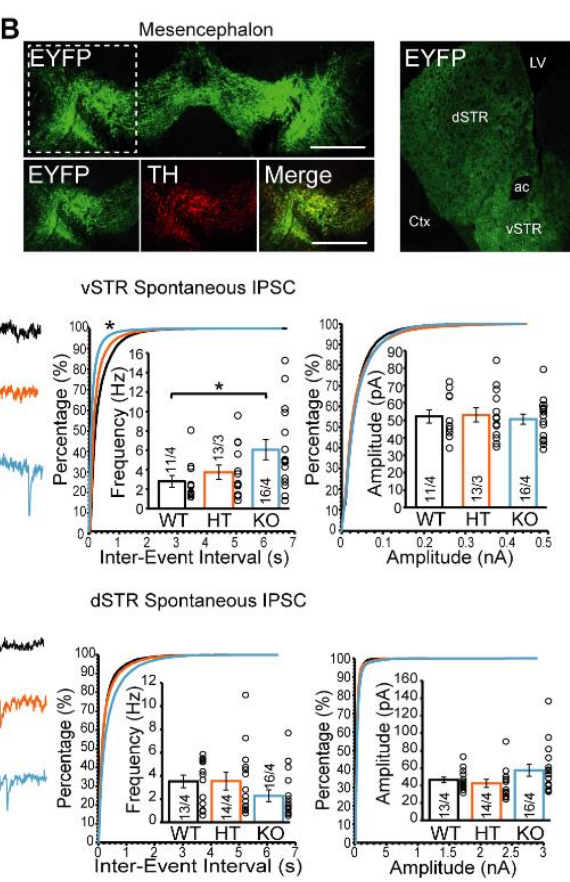
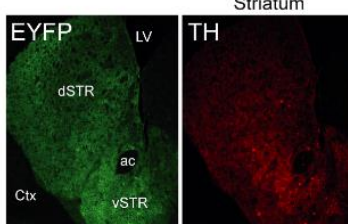

Merge

E
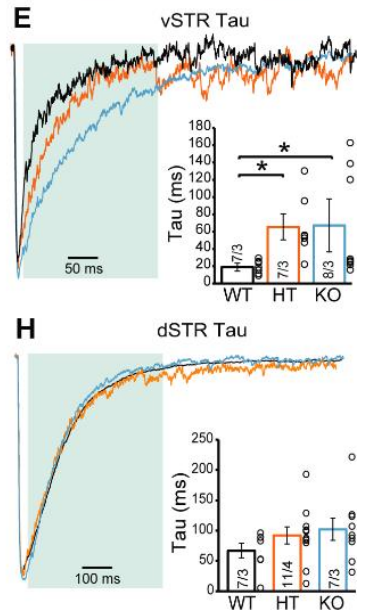
Figure 6 - Neurexins regulate GABA release from dopaminergic neurons in the ventral striatum. ASchematic representation of the experimental approach used for electrophysiological recordings; The green color represents the EYFP expression reporting ChR2 expression after AAV-transfection of the VTA. BPhotomicrographs illustrating the expression of EYFP-ChR2 in TH-positive (red) DA neurons located in the mesencephalon and their projections in the striatum. C- Representative traces (top) of IPSCs elicited by optical stimulation (o-IPSC), recorded in medium spiny neurons (MSNs) of acute ventral striatal slices from WT, HT, or KO mice. Summary graph of o-IPSC amplitude (bottom) shows a significant genotype effect (WT vs. HT: $* * \mathrm{p}=0.0017$; WT vs. KO: $* * * \mathrm{p}=0.0001$ ) (Peak Amplitude: $\mathrm{WT}=-40.02 \pm 4.7 \mathrm{pA}$, HT $=-91.99 \pm 14.9 \mathrm{pA}, \mathrm{KO}=-136.32 \pm 30.62$, Mean \pm SEM.). D- Representative traces (left) of spontaneous IPSCs (sIPSC) recorded in ventral striatal MSNs. Cumulative distribution plots of sIPSC inter-event intervals (middle, WT vs. KO: ${ }^{*} \mathrm{p}=0.038$ ) and amplitudes (right); insets: summary graphs of average sIPSC frequency (middle, WT vs. KO: $\left.{ }^{*} \mathrm{p}=0.04\right)$ (sIPSC frequency, WT $=2.79 \pm 0.61 \mathrm{~Hz}, \mathrm{HT}=$ $3.72 \pm 0.74 \mathrm{~Hz}, \mathrm{KO}=6.06 \pm 1.04 \mathrm{~Hz}$, Mean \pm SEM) and amplitude (right). E - Representative traces and summary graph of o-IPSC decay time constant in ventral striatal MSNs, showing an increase in rate to return to baseline (oIPSC, decay tau: $\mathrm{WT}=18.9 \pm 2.8 \mathrm{~ms}$, $\mathrm{HT}=65.4 \pm 13.5 \mathrm{~ms}$. $\mathrm{KO}=67.2 \pm 21.9 \mathrm{~ms}$. Mean \pm SEM). F -Representative traces (left) of o-IPSCs recorded in MSNs of acute dorsal striatal slices from WT, HT or KO mice. The summary graph of o-IPSC amplitude (bottom) shows no genotype effect (Peak Amplitude: $\mathrm{WT}=-528.50 \pm 187.31 \mathrm{pA}, \mathrm{HT}=-219.68 \pm 54.87 \mathrm{pA}, \mathrm{KO}=-138.03 \pm 34.57$, Mean \pm SEM). G- Representative traces (left) of sIPSCs recorded in dorsal striatal MSNs. Cumulative distribution plots of sIPSC inter-event intervals (middle) and amplitudes (right); insets: summary graphs of average sIPSC frequency (middle) and amplitude (right). Summary graphs show no genotype effect $\mathbf{H}$ Representative traces and summary graph of o-IPSC decay time in dorsal striatal MSNs shows no change in tau for both HT and KO compared to the WT group. Data in summary graphs are presented as mean \pm SEM; statistical comparisons were performed with One-Way ANOVA $(* \mathrm{P}<0.05 ; * * \mathrm{P}<0.01 ; * * * \mathrm{P}<0.001$; non-significant comparisons are not identified). Tukey's correction was used for all multiple comparisons. The Kruskal-Wallis non-parametric test was used to compare cumulative distributions in $\mathbf{D}$ and $\mathbf{G}$. Numbers in bars indicate the number of cells/mice. Each open circle in the summary graphs represents the averaged recording of each cell.

Closer analysis of the kinetics of GABA-mediated oIPSCs in the vSTR revealed a significant increase of oIPSC decay time (Fig. 6E, S5A-D; One-way ANOVA, F(2, 21) = 4.43, $p$ $=0.02)$ and decay time constant $($ Fig. S5; One-way ANOVA, F $(2,19)=5.55, p=0.013)$ in both DAT::NrxnsKO and DAT::NrxnsHET mice. These findings suggest that neurexin deletion in vSTR DAergic terminals enhances GABA release from DA terminals and prolongs GABAergic activity in MSNs.

As our manipulation affected the entire mesolimbic pathway, we also performed parallel optical stimulation and recordings in the dorsal striatum. We observed no statistically significant changes in oIPSC amplitude in DAT::NrxnsKO mice in the dSTR (Fig. 6F; Kruskal-Wallis Test, 
$\mathrm{H}(3)=3.4, p=0.18)$. Spontaneous and electrically-evoked GABA IPSCs were also unaltered (Fig. 6G, Fig. S3C and S3D), as was oIPSC decay time constant (Fig. 6H and S5E-H; One-way ANOVA, $\mathrm{F}(2,24)=1.2, p=0.32)$.

Together these results suggest that Nrxns act as regulators of GABA co-transmission by DA neurons in a region-specific manner. Further work will be required to identify the origin of this selectivity.

\section{Optically evoked excitatory transmission is unaltered in the striatum of DAT::NrxnsKO mice.}

We also examined glutamate release by DA neurons in the vSTR and dSTR. We did not detect genotype differences in optically-evoked EPSCs (oEPSCs) (Fig. 7A; One-way ANOVA, $\mathrm{F}(2,30)=1.01, p=0.37,7 \mathrm{~B} ;$ One-way ANOVA, $\mathrm{F}(2,20)=0.8, p=0.46)$. The frequency and amplitude of spontaneous EPSCs (sEPSCs) was also unchanged (Fig. 7C, 7D). The paired-pulse ratio and input-output relationship of electrically-evoked IPSCs were similarly unchanged (Fig. S6). These results suggest that Nrxns do not have a major role in regulating glutamate release from DA neurons. However, we detected a significant increase of the amplitude of EPSCs evoked by local electrical stimulation (eEPSC) in the ventral (Fig. S3B; One-way ANOVA, $\mathrm{F}(2,30)=4.8, p$ $=0.01$ ) but not the dorsal (Fig. S3D; One-way ANOVA, $\mathrm{F}(2,29)=0.02, p=0.98$ ) striatum. This observed increase in eEPSC amplitude opens the possibility that deletion of Nrxns impacts the development of DAergic projections to non-striatal regions that project to vSTR. 
A

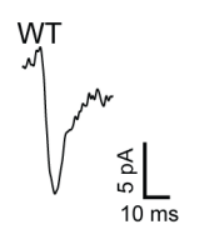
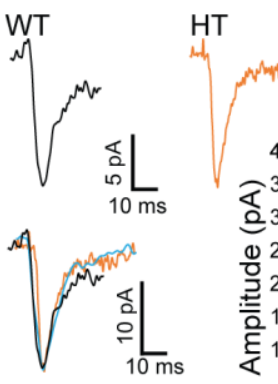

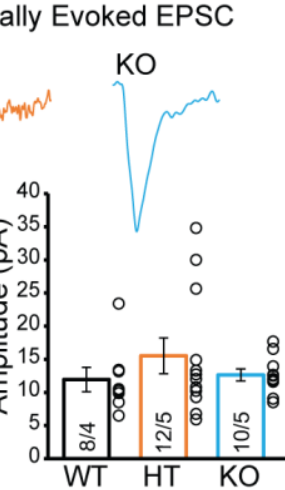

B dSTR Optically Evoked EPSC
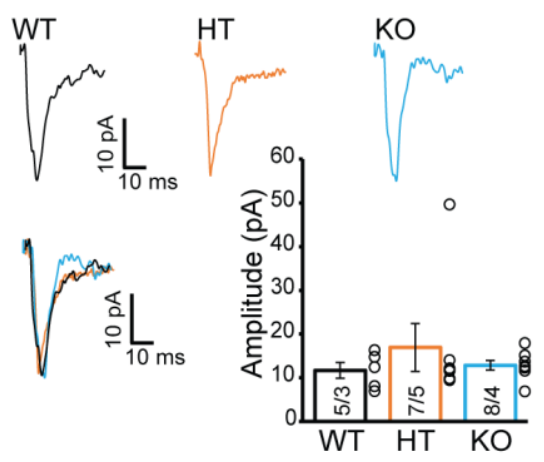

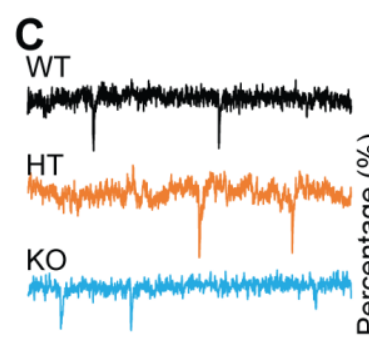

豆

vSTR Spontaneous EPSC
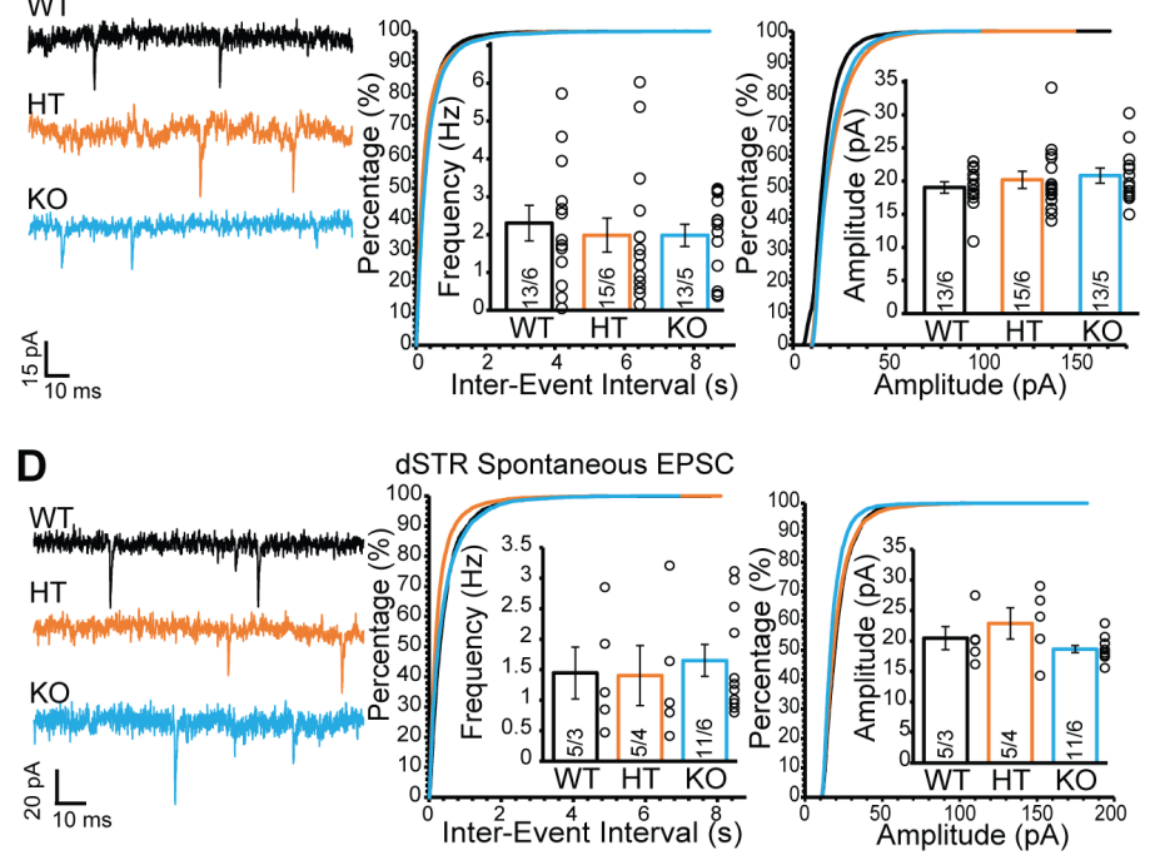

Figure 7 - Loss of neurexins does not influence glutamate release from dopamine neurons in the ventral and dorsal striatum. A- Representative traces (top) of EPSCs elicited by optical stimulation (oEPSCs) and recorded in ventral striatal MSNs. Summary graph of o-EPSC amplitudes (bottom) shows no genotype effect. B- Representative traces (top) of o-EPSCs recorded in dorsal striatal MSNs. Summary graph of o-EPSC amplitudes (bottom) shows no genotype effect. C- Representative traces (left) of spontaneous EPSCs (sEPSC) recorded in ventral striatal MSNs. Cumulative distribution plots of sEPSC inter-event intervals (middle) and amplitudes (right); insets: summary graphs of average sEPSC frequency (middle) and amplitude (right). D- Representative traces (left) of spontaneous EPSC (sEPSC) recorded in dorsal striatal MSNs. Cumulative distribution plots of sEPSC inter-event intervals (middle) and amplitudes (right); insets: summary graphs of average sEPSC frequency (middle) and amplitude (right). Data in summary graphs are provided as mean \pm SEM. Statistical comparisons were performed with OneWay ANOVA ( $* \mathrm{P}<0.05 ; * * \mathrm{P}<0.01 ; * * * \mathrm{P}<0.001$; non-significant comparisons are not labeled). Tukey's correction was used for all multiple comparisons. 


\section{Altered GABA uptake and VMAT2 suggest a possible mechanism underlying increased}

\section{GABA release in Nrxns KO mice.}

The region-specific increase of GABA release from DA axons in DAT::NrxnsKO mice, identified in our optogenetic experiments, could result from different mechanisms. One possibility is that loss of Nrxns induced differential adaptations in the expression of some of the postsynaptic partners of Nrxns, including NLs. However, using qRT-PCR, we did not detect major changes in expression of these genes in microdissected vSTR or dSTR, except for a small decrease in collybistin and LRRTM3 mRNA in DAT::NrxnsKO mice (unpaired t-test, $p=0.021$ and $p=0.014$, respectively) (Fig. S7A and S7B).

While DA neurons have the capacity to co-release GABA, it is well established that they do not synthesize it using glutamic acid decarboxylase and do not express the vesicular GABA transporter (Tritsch et al., 2012; Tritsch et al., 2014). Instead, they have been shown to use plasma membrane transporters to uptake GABA from the extracellular medium and VMAT2 to package it into synaptic vesicles (Tritsch et al., 2012; Tritsch et al., 2014). We therefore used a GABA uptake assay using primary DA neurons and quantified VMAT2 levels in the striatum.

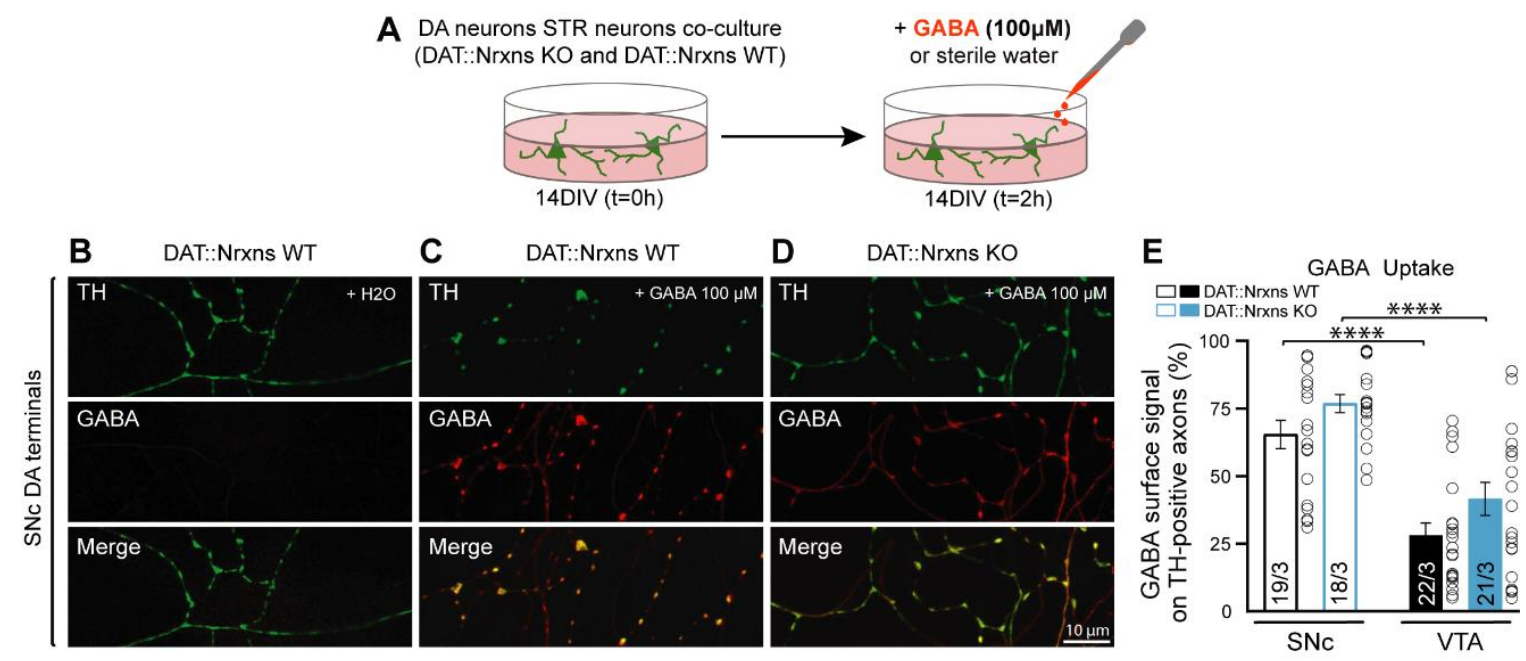


Figure 8 - GABA uptake from cultured DA neurons is unchanged after conditional deletion of all neurexins. A - Schematic representation of the experimental procedure for the GABA uptake assay in VTA-vSTR co-cultures or in SNc-dSTR co-cultures. B - D- Immunocytochemistry of SNc DA neurons from Nrxn123 WT (B and C) and DAT::NrxnsKO mice (D) for tyrosine hydroxylase (TH, green) and gamma-aminobutyric acid (GABA, red). Experiments on VTA-vSTR co-cultures are not illustrated. E Summary graph representing the quantification of GABA immunoreactivity signal surface in TH-positive axons for VTA and SNc DA neurons from DAT::NrxnsWT and KO cultures. $\mathrm{N}=18-22$ axonal fields from 3 different neuronal co-cultures. The number of observations represents the number of fields from TH-positive neurons examined. For all analyses, plots represent the mean \pm SEM. Statistical analyses were carried out by 2 -way ANOVAs followed by Tukey's multiple comparison test. (*p $<0.05$; **p $<0.01$; $* * * \mathrm{p}<0.001 ; * * * * \mathrm{p}<0.0001)$

GABA uptake was estimated using cultures prepared from DA neurons co-cultured with vSTR or dSTR neurons. Neurons were incubated with GABA $(100 \mu \mathrm{M})$ for $2 \mathrm{~h}$, rapidly washed and fixed before quantification of GABA immunoreactivity in these neurons, evaluating the proportion of TH signal in DA axons covered by GABA immunoreactivity in comparison to a control group treated with $\mathrm{H}_{2} \mathrm{O}$ (Fig. 8A). This treatment induced a robust increase in GABA immunoreactivity in DA neuron axons (Fig. 8B to 8D). Interestingly, SNc DA neurons globally showed a larger GABA uptake compared to VTA DA neurons (Fig. 8E; two-way ANOVA, main effect of region, $\mathrm{F}(1,76)=53.35, p<0.001)$. Furthermore, we observed a global increase of GABA uptake in DAT::NrxnsKO DA neurons compared to DAT::NrxnsWT DA neurons (two-way ANOVA, main effect of genotype, $\mathrm{F}(1,76)=6.25, p=0.014)$.

We next examined the level of VMAT2, TH and DAT in DA neuron axons in the striatum of DAT::NrxnsKO mice compared to WT controls. A first global quantification of protein levels by Western Blot (Fig. S8A and S8E), revealed a lack of overall change in the levels of TH and VMAT2 in DAT::NrxnsKO mice, in both vSTR and dSTR tissues (Fig. S8B, S8C, S8F and S8G). However, DAT levels were significantly reduced in the vSTR (Fig. S8A and S7D; unpaired t-test, $\left.\mathrm{t}_{10}=2.79 ; p=0.019\right)$. We also observed a tendency for a similar decrease in DAT in the dSTR (Fig. S8E and S8H; unpaired t-test, $\mathrm{t}_{10}=1.93 ; p=0.081$ ). 
To gain more region-specific insight in the levels of these proteins, we measured the intensity and surface area for these markers in a series of 3 striatal brain sections ranging from bregma +0.74 to bregma $-0.82 \mathrm{~mm}$, with a total of 7 different regions in each hemisphere (Fig. 9A). In this experiment, all sub-regions were compared and analyzed separately. First, TH signal intensity (Fig. 9B, 9C and 9F) and TH surface area (Fig. 9G) were unchanged in both dSTR and vSTR. For VMAT2 immunoreactivity (Fig. 9B and 9C), surface area was increased in both the vSTR and in the rostral part of the dSTR for KO mice (Fig. 9I; vSTR, unpaired t-test, Welch's correction, $p=0.045$; dSTR3, unpaired t-test, Welch's correction, $p=0.045$ ), while intensity was unchanged (Fig. 9H). In contrast, DAT immunostaining showed a decrease of signal intensity in the vSTR (Fig. 9D and 9J; vSTR, unpaired t-test, $p=0.039$ ) and in the rostral and caudal parts of the dSTR of DAT::NrxnsKO mice (Fig. 9D, 9E and 9J; dSTR1, unpaired t-test, $p=0.025$; dSTR3, unpaired t-test, Welch's correction, $p=0.024)$. The DAT surface area was also significantly decreased in the vSTR and in the caudal part of the dSTR (Fig. 9K; vSTR, unpaired t-test, $p=0.033$; dSTR3, unpaired t-test, Welch's correction, $p=0.030$ ).

Together, our observation of increased GABA uptake and increased VMAT2 in the vSTR could represent an explanation for the observed increase in GABA release by DA neuron axons in this part of the striatum. 
A

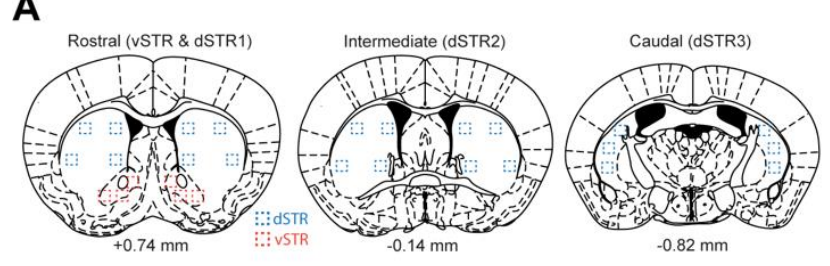

B Ventral Striatum

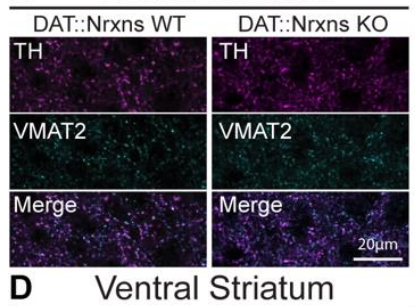

$\frac{\text { D Ventra }}{\text { DAT::Nrxns WT }}$

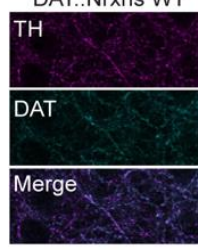

C

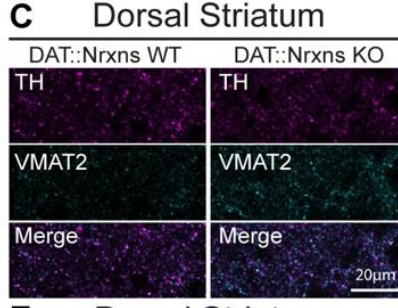

E Dorsal Striatum

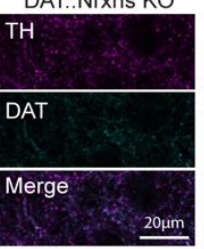

DAT::Nrxns WT

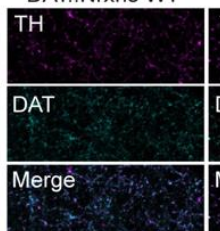

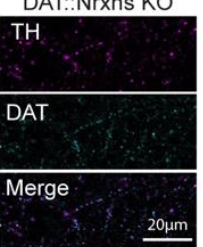
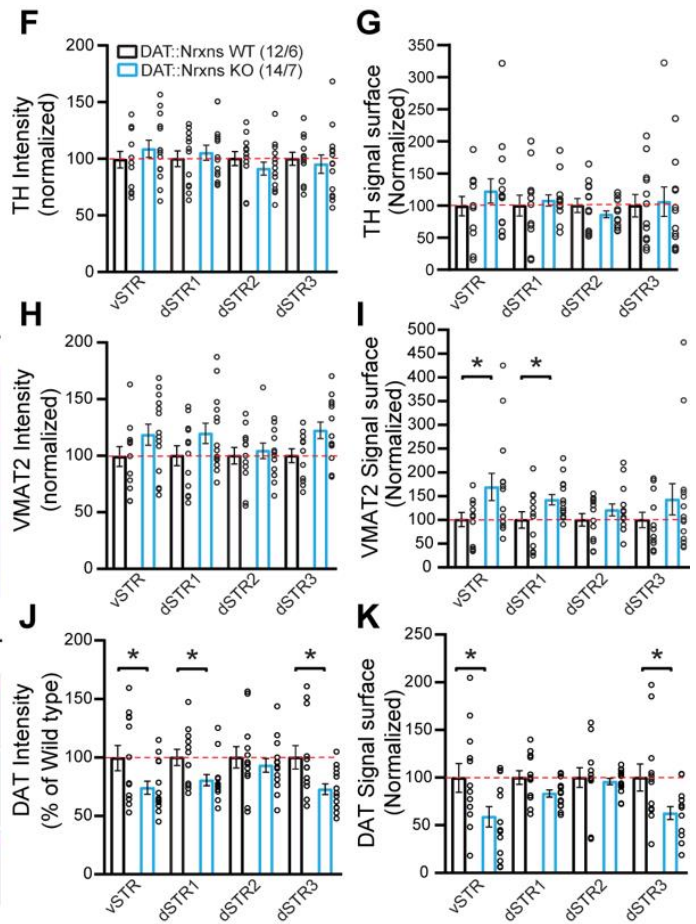

Figure 9 - Increased VMAT2 but decreased DAT expression in DA axon terminals lacking neurexins. A-Schematic representation of striatal slices used for immunohistochemistry characterization. Surface and intensity for each signal were measured in a series of 3 different striatal slices ranging from bregma +0.74 to bregma $-0.82 \mathrm{~mm}$, with a total of 14 different spots for each hemisphere. B and $\mathbf{C}$ Immunohistochemistry of ventral $(\mathbf{B})$ and dorsal $(\mathbf{C})$ striatal slices from 8-week-old DAT::NrxnsKO and DAT::NrxnsWT mice (60X confocal) using tyrosine hydroxylase (TH, purple) and vesicular monoamine transporter 2 (VMAT2, blue) antibodies. D and $\mathbf{E}$ - Immunohistochemistry of ventral (B) and dorsal (C) striatal slices from DAT::NrxnsKO and DAT::NrxnsWT mice using TH (purple) and the dopamine transporter (DAT, blue) antibodies. F to K - Quantification of signal surface (\% of WT) for TH, VMAT2 and DAT in the different striatal regions examined: "vSTR, dSTR1, dSTR2 and dSTR3" (DAT::NrxnsKO $=14$ hemispheres $/ 7$ mice; DAT: $:$ NrxnsWT $=12$ hemispheres/ 6 mice). TH signal intensity: vSTR $=108.7$ $\pm 7.48 \%$; dSTR $1=105.2 \pm 6.65 \%$; dSTR2 $=91.18 \pm 5.71 \%$; dSTR $3=95.26 \pm 8.05 \%$ of control. TH surface area: $\mathrm{vSTR}=122.6 \pm 19.07 \%$; dSTR $1=107.9 \pm 8.62 \% ; \mathrm{dSTR} 2=86.38 \pm 5.42 \%$; dSTR $3=106.20 \pm 22.82 \%$ of control. VMAT2 intensity: vSTR= $118.4 \pm 9.30 \%$; dSTR1 $=119.7 \pm 8.96 \%$; dSTR2=104.3 $\pm 6.91 \%$; dSTR3 $=122.3 \pm 7.24 \%$ of control. VMAT2 surface area: $v S T R=169.3 \pm 28.42 \%$; dSTR1 $1=142.4 \pm$ $11.14 \%$; dSTR2 $=120.8 \pm 12.73 \%$; dSTR3 $=143.3 \pm 32.98 \%$. DAT signal intensity: $v S T R=74.07 \pm 20.98 \%$; dSTR $1=80.50 \pm 17.77 \%$; dSTR2 $=93.17 \pm 21.96 \%$; dSTR3 $=72.80 \pm 17.08 \%$. DAT surface area: vSTR=58.92 \pm 10.72\%; dSTR1=60.80 $\pm 3.87 \%$; dSTR=295.98 $\pm 3.38 \% ;$ dSTR3=62.78 $\pm 6.71 \%$. Statistical analysis was carried out by unpaired t-test for each substructure. Error bars represent \pm S.E.M. (ns, non-significant; *, p < 0.05; **, p < 0.01; ***, p < 0.001; ****, p < 0.0001). 


\section{Discussion}

Since the initial discovery of Nrxns (Ushkaryov et al., 1992), multiple studies have explored the roles of these proteins in synapse formation, function, maintenance, and plasticity. Most of these studies have been conducted on glutamatergic or GABAergic neurons, with no evaluation of their role in modulatory neurons such as DA, serotonin, norepinephrine, or acetylcholine neurons, whose connectivity is strikingly different and markedly less synaptic (Ducrot et al., 2021). We expected that new insights could be gained by studying the role of these trans-synaptic proteins in modulatory neurons. In the present study, we utilized the Cre-lox system by combining the triple conditional Nrxn mouse line (Chen et al., 2017) with a DAT-Cre mouse line to selectively delete Nrxns in DA neurons and examine the impact of this deletion using a combination of primary neuronal cultures, electron microscopy, behavioral assessments, patchclamp recordings of striatal MSNs, fast scan cyclic voltammetry, and immunohistochemistry. We found that while loss of Nrxns does not markedly impair the basic development and axonal ultrastructure of DA neuron terminals in vitro and in vivo, it does lead to region-specific changes in their axonal connectivity. We also found that loss of Nrxns is associated with impaired DA neurotransmission in the brain of adult mice, as revealed by a reduced rate of DA reuptake after electrically-evoked DA release and with impaired amphetamine-induced locomotion. Patch-clamp recordings of GABA and glutamate release by DA neuron axons also revealed an unexpected increase of GABA co-release. Together these findings suggest that, although Nrxns are not critical for many aspects of the basic axonal development and synapse formation of DA neurons, they act as key regulators of GABA and DA signaling in these neurons.

Nrxns are not required for the basic morphological development of DA neurons but regulate their connectivity 
Nrxns have been previously suggested to contribute to the development of synapses (Missler et al., 2003; Li et al., 2007; Etherton et al., 2009; Aoto et al., 2015; Chen et al., 2017). In a first series of experiments, we examined whether loss of Nrxns impairs the morphological development of DA neurons. Our results did not identify major changes in the global axonal development of these neurons. However, we found that the proportion of bassoon-positive terminals, established by SNc DA neurons, was reduced after loss of Nrxns. Furthermore, the proportion of these terminals contacting PSD95 postsynaptic domains was also reduced, suggesting that these proteins play a role in regulating the connectivity of DAergic terminals, and the formation of active zones. These findings are in line with recent results suggesting a possible role of Nrxns in the organizational features of the active zone (Luo et al., 2020). How Nrxns organize active zone assembly is presently unknown, but a previous study suggested that these proteins can interact indirectly with active zone proteins through calcium/calmodulin-dependent serine protein kinase 3 and membrane-associated guanylate kinase 2 (CASK) (Hata et al., 1996). Further in vivo experiments will be needed to evaluate this possibility more directly using transmission electron microscopy or other types of high-resolution microscopy approaches.

Experiments performed in vitro allowed us to more closely examine the propensity of DA terminals to interact with GABA and glutamate postsynaptic domains, especially considering the capacity of these neurons to co-release glutamate and GABA in a subset of their synaptic terminals (Sulzer et al., 1998; Dal Bo et al., 2008; Descarries et al., 2008; Stuber et al., 2010; Tritsch et al., 2012). We hypothesized that Nrxns play a critical role in the establishment of excitatory and inhibitory synapses by DA neurons. Quantification of the proportion of TH-positive terminals overlapping with the glutamatergic postsynaptic marker PSD95 revealed a decrease in the proportion of SNc DA neuron terminals contacting a PSD95 or gephyrin postsynaptic domain in cultures prepared from DAT::NrxnsKO mice. However, results obtained with transmission electron microscopy in striatal sections did not reveal any notable differences in the ultrastructure of DA 
terminals in these mice when compared to wild-type controls. However, these experiments did not distinguish between DA neuron terminals containing vesicular glutamate transporters and those only containing DA markers. Further immuno-EM experiments would be required to examine VGLUT2-positive DA neuron terminals more specifically. These data suggest that although Nrnxs are not required for the basic structure of DA neuron terminals, they can regulate DA neuron connectivity in a region-specific manner. Our observations of region-specific alterations concur with results from the first in vivo study on the conditional triple Nrxn deletion, published by Chen and colleagues in 2017 (Chen et al., 2017), revealing that removal of Nrxns resulted in a significant decrease in the number of parvalbumin-positive synapses in the cortex and of excitatory synapses formed by the climbing fibers innervating purkinje neurons in the cerebellum. Our observation of an absence of major structural changes in the DA neuron terminals after deletion of Nrxns is also in keeping with previous reports obtained with the single, double or triple deletion of Nrxn in glutamatergic or GABAergic neurons (Missler et al., 2003; Chen et al., 2017). Another recent study using the triple Nrxn mice also reported a lack of impact of Nrxn deletion on synapse formation at the calyx of Held (Luo et al., 2020). Taken together with our results, we similarly conclude that Nrxns play a synapse-specific regulatory role in synapse formation and maintenance, but do not act as direct drivers of synapse formation.

\section{Dopamine transporter expression and function are altered in DAT::NrxnsKO mice}

To obtain direct functional insight into the roles of Nrxns in DAergic neurotransmission, we performed FSCV recordings in the vSTR and dSTR. Our data revealed that peak electricallyevoked DA overflow was not reduced in the absence of Nrxns, suggesting that Nrxn123 do not play an obligatory role in the DA release mechanism and the initial formation and function of DA neuron varicosities, in line with our in vitro results. The reduction in peak DA overflow in DAT::NrxnsHET mice is puzzling and remains presently unexplained. One possibility is that 
deletion of a single Nrxn123 allele was insufficient to prevent the occurrence of possible compensatory mechanisms induced in full knockouts. Although peak DA release was not impaired in the absence of Nrxns, we found a systematic impairment in DA reuptake in both DAT::NrxnsKO and DAT::NrxnsHET mice compared to DAT::NrxnsWT mice. This finding of impaired DAT function is particularly intriguing in the context of our observation that DAT::NrxnsKO mice show a robust impairment in amphetamine-induced locomotion. Amphetamine is well known to increase extracellular DA levels by impairing vesicular storage of DA and inducing reverse transport through the DAT. It is thus possible that Nrxns regulate the stability and function of the DAT in DA neuron axon terminals, perhaps through DAT's PDZ domain, and that in the absence of Nrxns, DAT function and positioning in terminals is impaired (Sorensen et al., 2021).

\section{Regulatory role of Nrxns in GABA release by dopamine neurons}

One of the most intriguing observations in the present study is the region-specific increase of evoked GABA release from VTA DA neuron terminals in the vSTR. The origin of this selectivity is presently unclear but could arise from several possibilities including, differential expression of Nrxn splice variants or their postsynaptic ligands and selective binding affinity in the dorsal or ventral striatum. Multiple studies over the past decade reported similar conclusions, where different Nrxn isoforms were proposed to regulate various aspects of synapse organization and function (Ullrich et al., 1995). Further studies would be needed to analyze the function of specific splice variants in each region. It is known that Nrxn splice variants are differentially expressed in different brain regions, and this determines the preference for different postsynaptic binding partners. A possible hypothesis to explain our observations is that one or more Nrxns act as a repressor of GABA co-transmission and thus regulate the excitatory/inhibitory neurotransmission balance of the axonal domain of DA neurons. Indeed, previous work has shown that Nrxns physically and functionally interact with $\mathrm{GABA}_{\mathrm{A}}$ receptors and that overexpression of Nrxns decreases inhibitory 
but not excitatory synaptic strength (Zhang et al., 2010). These results are consistent with our observations showing that after removal of all Nrxns, GABAergic synaptic events evoked by stimulation of DA neuron terminals are increased. Further work, including rescue experiments, would be needed to test this hypothesis directly and determine which Nrxn is involved in this mechanism.

Interpretation of some of our findings needs to be made considering that the DAT promoter becomes active during the late embryonic period. Embryonic deletion of Nrxns in DA neurons could thus have altered the development of these neurons and of target regions. Notably, our observation of an increase in electrically evoked EPSCs and sIPSCs in the vSTR of KO mice could potentially result from alterations in DA neuron projections to non-striatal regions such as the cortex.

The regional specificity of our data raises intriguing questions regarding functional differences between the mesolimbic and nigrostriatal projections. We observed an increase in GABA-mediated oIPSCs only in the vSTR. Furthermore, basal GABA uptake was higher in SNc than VTA DA neurons and baseline oIPSC amplitude was higher in the dSTR than the vSTR. Together, these observations suggest that there may be intrinsic differences in the structure and function of GABA release sites in these two circuits.

The role of Nrxns in regulating glutamate synapses established by DA neuron axons is less clear. Although we detected a decrease in the propensity of DA neuron axonal varicosities to contact PSD95 postsynaptic domains, we did not detect a decrease in optically-evoked glutamatemediated EPSCs in striatal neurons in slices prepared from DAT::NrxnsKO mice. This dichotomy suggests that although structural changes may have happened at these glutamatergic terminals, this did not translate into functional changes. These findings highlight the complexity and the diversity of the role of Nrxns at synapses, in line with much recent work (Chen et al., 2017; Luo et al., 2020). 
It would be interesting to complement our work by recording separately from striatal MSNs of the direct and indirect basal ganglia pathway (Gerfen and Surmeier, 2011), as some of the heterogeneity in our results on GABA and glutamate synaptic events may derive from differences in the roles of Nrxns in these two pathways. Previous work has shown that DA regulates tonic inhibition in striatal MSNs, and this regulation differs between D1 and D2 MSNs (Janssen et al., 2009). Given our results showing changes in GABA release from DA terminals, investigating tonic inhibition of D1 and D2 MSNs within the context of Nrxn deletion would be of interest for future work.

Mechanistically, the increase in GABA IPSCs we detected in DAT::NrxnsKO mice most likely resulted from presynaptic changes. We detected an increase in GABA uptake by cultured DA neurons and an increase in VMAT2 levels, detected in striatal sections. Together these two mechanisms could lead to increased GABA uptake by DA neuron terminals and increased GABA vesicular packaging through a VMAT2-dependent process. We also confirmed that oIPSCs in the vSTR were blocked almost entirely by reserpine, a VMAT2 inhibitor. Importantly, the increase in oIPSC amplitude in the vSTR was not accompanied by changes in eIPSC amplitude or sIPSC amplitude. This further supports the idea that the changes observed in GABA-mediated currents resulted specifically from an increase in presynaptic GABA release from DA neurons. However, the prolongation of optically-evoked IPSCs that we also detected in slices prepared from DAT::NrxnsKO mice points to a prolongation of $\mathrm{GABA}_{\mathrm{A}}$ receptor opening. Further experiments will be required to identify the pre- or postsynaptic origin of this effect.

Alterations in DA neuron connectivity following Nrxn deletion may also regulate the intrinsic vulnerability of DA neurons, as suggested by our observation of reduced survival of DA neurons in primary cultures established from DAT::NrxnsKO mice. However, we did not observe a decrease in TH signal in the striatum of these mice in vivo. 
Together, our findings shed new light on the role of these cell-adhesion molecules in DA neuron connectivity. We conclude that Nrxns are dispensable for the initial establishment of axon terminals and synapses by DA neurons but play a role in regulating both DAT function and GABA release by DA neurons. Only a small subset of axon terminals established by DA neurons adopt a synaptic configuration. We conclude that the formation of such synaptic contacts must be regulated by other transsynaptic proteins. Potential candidates include proteins from the leucocyte antigen receptor - protein tyrosine-phosphatases (LAR-PTP) family. As we observed a decrease in bassoon-positive terminals established by DA neurons in the absence of Nrxns, it remains possible that these trans-synaptic proteins play a role in regulating active zone assembly in a subset of terminals established by DA neurons. Further experiments will be needed to determine if this assembly is subject to control by presynaptic signals or if it is controlled indirectly by trans-synaptic signaling via postsynaptic signals.

\section{STAR methods}

\section{Animals}

All procedures involving animals and their care were conducted in accordance with the Guide to care and use of Experimental Animals of the Canadian Council on Animal Care. The experimental protocols were approved by the animal ethics committees of the Université de Montréal (CDEA). Housing was at a constant temperature $\left(21^{\circ} \mathrm{C}\right)$ and humidity $(60 \%)$, under a fixed $12 \mathrm{~h} \mathrm{light/dark}$ cycle with food and water available ad libitum.

\section{Generation of triple Neurexins cKO mice in DA neurons}

All experiments were performed using mice generated by crossing DAT-IRES-Cre transgenic mice (Jackson Labs, B6.SJL-Slc6a3tm1.1 (Cre)Bkmn/J, strain 006660) with Nrxn123loxP mice [for details see (Chen et al., 2017)]. Briefly, conditional knock-out (cKO) mice were produced as a 
result of CRE recombinase driving a selective excision of Nrxn-1, Nrxn-2 and Nrxn-3 genes in DA neurons and giving three different genotypes: Nrxn123 KO, Nrxn123 HET and Nrxn123 WT mice. The Nrxn123flox/flox mice were on a mixed Cd1/BL6 genetic background. The DAT-IRES-Cre mice were on a C57BL/6J genetic background. Except for culture experiments, only males were used.

\section{Genotyping}

Mice were genotyped with a KAPA2G Fast HotStart DNA Polymerase kit (Kapa Biosystem). The following primers were used: DAT-IRES-Cre: Common 5' TGGCTGTTGTGTAAAGTGG3', wild-type reverse 5'GGACAGGGACATGGTTGACT 3' and knock-out reverse 5'CCAAAAGACGGCAATATGGT-3', Nrxn-1 5'-GTAGCCTGTTTACTGCAGTTCATT-3' and 5'-CAAGCACAGGATGTAATGGCCTT-3', Nrxn-2 5'-CAGGGTAGGGTGTGGAATGAG-3' and 5'-GTTGAGCCTCACATCCCATTT-3', Nxn3 5'-CCACACTTACTTCTGTGGATTGC-3' and 5'-CGTGGGGTATTTACGGATGAG-3'.

\section{Primary neuronal co-cultures}

For all experiments, postnatal day 0-3 (P0-P3) mice were cryoanesthetized, decapitated and used for co-cultures as previously described (Fasano et al., 2008). Primary VTA or SNc DA neurons were obtained from Nrxn123 KO or Nrxn123 WT pups and co-cultured with ventral striatum and dorsal striatum neurons, respectively from Nrxn123 KO or Nrxn123 WT pups. Neurons were seeded on a monolayer of cortical astrocytes grown on collagen/poly-L-lysine-coated glass coverslips. All cultures were incubated at $37^{\circ} \mathrm{C}$ in $5 \% \mathrm{CO}_{2}$ and maintained in $2 / 3$ of Neurobasal medium, enriched with $1 \%$ penicillin/streptomycin, 1\% Glutamax, 2\% B-27 supplement and 5\% fetal bovine serum (Invitrogen) plus $1 / 3$ of minimum essential medium enriched with $1 \%$ 
penicillin/streptomycin, $1 \%$ Glutamax, 20mM glucose, $1 \mathrm{mM}$ sodium pyruvate and $100 \mu \mathrm{l}$ of MITO+ serum extender. All primary neuronal co-cultures were used at 14DIV.

\section{Immunocytochemistry on cell cultures}

Cultures were fixed at 14-DIV with 4\% paraformaldehyde (PFA; in PBS, pH-7.4), permeabilized with $0,1 \%$ triton $\mathrm{X}-100$ during 20 -min, and nonspecific binding sites were blocked with $10 \%$ bovine serum albumin during 10-min. Primary antibodies were: mouse anti-tyrosine hydroxylase (TH) (1:2000, Sigma), rabbit anti-TH (1:2000, Chemicon), rabbit anti-synaptotagmin 1 (Syt1) (1:1000, Synaptic Systems) and rabbit anti-vesicular monoamine transporter 2 (VMAT2) (1:1000, gift of Dr. Gary Miller, Colombia University). To improve the immunoreactivity of the synaptic markers PSD95, gephyrin and bassoon, a set of cultures were fixed with 4\% PFA together with 4\% sucrose. For these experiments, the primary antibodies were mouse anti-PSD95 (1:1000 Pierce antibody), mouse anti-gephyrin (1:1000, Synaptic Systems) and guinea pig anti-bassoon (1:1000, Synaptic Systems). These were subsequently detected using Alexa Fluor-488-conjugated, Alexa Fluor-546-conjugated, Alexa Fluor-568-conjugated or Alexa Fluor-647-conjugated secondary antibodies (1:500, Invitrogen).

\section{Transmission Electron Microscopy (TEM)}

Following i.p. injection of ketamine $(100 \mathrm{mg} / \mathrm{Kg})$ and xylazine $(10 \mathrm{mg} / \mathrm{Kg}), \mathrm{P} 70$ mice were transcardially perfused with $50 \mathrm{ml}$ of ice-cold sodium phosphate buffer saline (PBS; 0.1M; pH 7.4) followed by $150 \mathrm{~mL}$ of a mix composed of $4 \%$ paraformaldehyde and $0.1 \%$ glutaraldehyde diluted in PBS. Dissected brains were extracted and post-fixed overnight in $4 \%$ PFA at $4{ }^{\circ} \mathrm{C}$. Mouse brains were cut with a vibratome (model VT1200 S; Leica, Germany) into $50 \mu$ m-thick transverse sections. For TH immunostaining, $50 \mu \mathrm{m}$-thick sections taken through the striatum $(1.18 \mathrm{~mm}$ and $1.34 \mathrm{~mm}$ from bregma, according to the mouse brain atlas of Franklin \& Paxinos $1^{\text {st }}$ edition) were rinsed 
with PBS and pre-incubated for $1 \mathrm{~h}$ in a solution containing $2 \%$ normal goat serum and $0.5 \%$ gelatin diluted in PBS. Sections were then incubated overnight with a rabbit primary TH antibody (Millipore, catalogue no. AB152, 1/1000). Sections were rinsed and incubated during $2 \mathrm{~h}$ with a goat anti-rabbit secondary antibody (1/500) and directly coupled to a peroxidase (Jackson, catalogue no. 111-035-003). The peroxidase activity was revealed by incubating sections for 5 min in a $0.025 \%$ solution of $3,3^{3}$ diaminobenzidine tetrahydrochloride (DAB; Sigma-Aldrich, catalogue no. D5637) diluted in Tris-saline buffer (TBS; $50 \mathrm{mM} ; \mathrm{pH} 7.4$ ), to which $0.005 \%$ of $\mathrm{H}_{2} \mathrm{O}_{2}$ was added. The reaction was stopped by several washes in TBS followed by phosphate buffer (PB; $50 \mathrm{mM} ; \mathrm{pH}$ 7.4). At room temperature, sections were washed 3 times in $\mathrm{ddH}_{2} \mathrm{O}$ and incubated for $1 \mathrm{~h}$ in a solution composed of $1.5 \%$ potassium ferrocyanide and $2 \%$ osmium tetroxide (EMS) diluted in $\mathrm{ddH}_{2} \mathrm{O}$. After 3 rinses in $\mathrm{ddH}_{2} \mathrm{O}$, sections were incubated for $20 \mathrm{~min}$ in a filtered solution of $1 \%$ thiocarbohydrazide (Ted Pella) diluted in $\mathrm{ddH}_{2} \mathrm{O}$. Sections were then rinsed 3 times and incubated in $2 \%$ osmium tetroxide. After rinses in $\mathrm{ddH}_{2} \mathrm{O}$, sections were dehydrated in graded ethanol and propylene oxide and flat-embedded in Durcupan (catalogue no.44611-14; Fluka, Buchs, Switzerland) for $72 \mathrm{~h}$ at $60^{\circ} \mathrm{C}$. Trapezoidal blocs of tissue from the ventral striatum were cut from the resin flat-embedded TH-immunostained sections. Each quadrangular pieces of tissue were glued on the tip of resin blocks and cut into $80 \mathrm{~nm}$ ultrathin sections with an ultramicrotome (model EM UC7, Leica). Ultrathin sections were collected on bare 150-mesh copper grids and examined under a transmission electron microscope (Tecnai 12; Philips Electronic, Amsterdam, Netherlands) at $100 \mathrm{kV}$. Profiles of axon varicosities were readily identified as such by their diameter (larger than $0.25 \mu \mathrm{m}$ ) and their synaptic vesicles content. Using an integrated digital camera (MegaView II; Olympus, Münster, Germany), TH immunopositive axon varicosities were imaged randomly, at a working magnification of 9,000X, by acquiring an image of every such profile encountered, until 50 or more showing a full contour and distinct content were available for analysis, in each mouse. 


\section{Stereotaxic virus injections}

Nrxn123 KO, Nrxn123 HET and Nrxn123 WT mice (P30-45) were anesthetized with isoflurane (Aerrane; Baxter, Deerfield, IL, USA) and fixed on a stereotaxic frame (Stoelting, Wood Dale, IL, USA). Fur on top of the head was trimmed, and the surgical area was disinfected with iodine alcohol. Throughout the entire procedure, eye gel (Lubrital, CDMV, Canada) was applied to the eyes and a heat pad was placed under the animal to keep it warm. Next, bupivacaine $(5-\mathrm{mg} / \mathrm{ml}$ and 2-mg/Kg, Marcaine; Hospira, Lake Forest, IL, USA) was subcutaneously injected at the surgical site, an incision of about $1-\mathrm{cm}$ made with a scalpel blade and the cranium was exposed. Using a dental burr, one hole of 1-mm diameter was drilled above the site of injection [AP (anteriorposterior; ML (medial-lateral); DV (dorsal ventral), from bregma]. The following injection coordinates were used: SNc/VTA [AP $-3.0 \mathrm{~mm}$; ML $\pm 0.9 \mathrm{~mm}$; DV $-4.3 \mathrm{~mm}$ ]. Borosilicate pipettes were pulled using a Sutter Instrument, P-2000 puller, coupled to a 10 ul Hamilton syringe (Hamilton, $701 \mathrm{RN}$ ) using a RN adaptor (Hamilton, 55750-01) and the whole setup was filled with mineral oil. Using a Quintessential Stereotaxic Injector (Stoelting), solutions to be injected were pulled up in the glass pipette. For expression of ChR2 in DA neurons, $0.8-\mu 1$ (VTA/SNc) of sterile $\mathrm{NaCl}$ containing $1.3 \times 10^{12}$ viral particles/mL of AAV5-EF1a-DIO-hChR2(H134R)-EYFP (UNC GTC Vector Core, NC, USA) was injected bilaterally. After each injection, the pipette was left in place for 5-min to allow diffusion and then slowly withdrawn. A second batch of mice were injected twice bilaterally [AP $-2.8 \mathrm{~mm}$; ML $\pm 0.9 \mathrm{~mm}$; DV $-4.3 \mathrm{~mm}$ ] and [AP $-3.2 \mathrm{~mm} ; \mathrm{ML} \pm 1.5 \mathrm{~mm}$; DV $-4.2 \mathrm{~mm}$ ] with a total of four $0.5-\mathrm{uL}$ injections of the same viral preparation. This was done to improve the infection rate. Finally, the scalp skin was sutured and a subcutaneous injection of the anti-inflammatory drug carprofen (Rimadyl, $50-\mathrm{mg} / \mathrm{mL}$ at $5 \mathrm{mg} / \mathrm{kg}$ ) was given. Animals recovered in their home cage and were closely monitored for $72 \mathrm{~h}$. A second dose of carprofen $(5-\mathrm{mg} / \mathrm{kg})$ was given if the mice showed evidence of pain. 


\section{Electrophysiology and optogenetics}

Slice preparation: P70 - 80 mice were deeply anesthetized with isoflurane and quickly decapitated. Acute coronal slices $(300 \mu \mathrm{m})$ were obtained using a vibrating blade microtome (Leica V1200S) in ice-cold N-Methyl D-Glucamine (NMDG) cutting solution: containing (in mM): 110 NMDG, 20 HEPES, 25 glucose, $30 \mathrm{NaHCO}, 1.25 \mathrm{NaH} 2 \mathrm{PO} 4,2.5 \mathrm{KCl}, 5$ ascorbic acid, 3 Na-pyruvate, 2 Thiourea, $10 \mathrm{MgSO} 4-7 \mathrm{H} 2 \mathrm{O}, 0.5 \mathrm{CaCl}$, 305-310 mOsm, $\mathrm{pH}$ 7.4. Slices equilibrated in a homemade chamber for $2-3 \min \left(31^{\circ} \mathrm{C}\right)$ in the above solution and an additional $60 \mathrm{~min}$ in room temperature aCSF containing (in mM): $120 \mathrm{NaCl}, 26 \mathrm{NaHCO}, 1 \mathrm{NaH} 2 \mathrm{PO} 4,2.5 \mathrm{KCl}, 11$ Glucose, 1.3 MgSO4-7 H2O, and 2.5 CaCl2 (290-300 mOsm, $\mathrm{pH} 7.4)$ before being transferred to a recording chamber.

Whole-Cell Patch-Clamp: Recordings were obtained from medium spiny neurons (MSNs) in the dorsal and ventral striatum. Striatal MSNs were visualized under IR-DIC. Data were collected with a Multiclamp 700B amplifier, Digidata 1550B (Molecular devices), and using Clampex 11 (pClamp; Molecular Devices, San Jose, CA). All recordings were acquired in voltage clamp $\left(\mathrm{V}_{\mathrm{h}}=\right.$ $-70 \mathrm{mV})$ at $31^{\circ} \mathrm{C}$ and $\mathrm{QX}-314(1 \mathrm{uM})$ was used in all internal solutions to internally block sodiumchannels. Whole cell currents were acquired and sampled at $10 \mathrm{kHz}$ with a lowpass bessel filter set at $2 \mathrm{kHz}$ and digitized at $10 \mathrm{kHz}$. For excitatory currents (EPSCs), the patch pipette was filled with internal solution containing (in $\mathrm{mM}$ ): $135 \mathrm{CsMeSO} 4,8 \mathrm{CsCl}, 10 \mathrm{HEPES}, 0.25$ EGTA, 10 Phosphocreatine, 4 MgATP, and 0.3 NaGTP (295 - 305 mOsm, pH 7.2 with CsOH) and Picrotoxin $(50 \mu \mathrm{M})$ was added to aCSF. For inhibitory postsynaptic currents (IPSC), patch pipettes were filled with internal solution containing (in mM): $143 \mathrm{CsCl}$, 10 HEPES, 0.25 EGTA, 10 Phosphocreatine, $4 \mathrm{MgATP}$, and $0.3 \mathrm{Na}-2 \mathrm{GTP}$ (osmolarity 295 - 305, pH 7.2 with $\mathrm{CsOH}$ ) and CNQX (50 $\mu \mathrm{M})$ and AP5 $(10 \mu \mathrm{M})$ were added to aCSF. All pipettes $(3-4 \mathrm{M} \Omega)$ were pulled from borosilicate glass (Narishige PC-100). Patched cells were allowed a minimum of 3 min to stabilize following breakin and access resistance $(\mathrm{Ra})$ was monitored throughout the recording and cells with an increase of 
$>20 \%$ in Ra were discarded. Optically evoked synaptic currents were induced with 440nm wavelength LED light delivered through a 40X objective lens (Olympus BX51WI) at $0.1 \mathrm{~Hz}$ (5 ms pulse) and light intensity was adjusted using a LLE-SOLA-SE2 controller (Lumencore). Electrically evoked synaptic currents in MSNs were evoked using a bipolar stimulation electrode placed in the dorsal or ventral striatum using the following parameters: $0.1 \mathrm{~Hz}$ frequency, pulse duration $0.1 \mathrm{~ms}$. Input/output (I/O) curves were also obtained to compare synaptic strength. They were measured with a stimulation at a frequency of $0.1 \mathrm{~Hz}$ with intensity increments of $10 \mu \mathrm{A}$ (starting at $10 \mu \mathrm{A}$ and finishing at $100 \mu \mathrm{A}$ ) with 3 sweeps per increment. We also measured pairedpulse ratio (PPR) to examine presynaptic probability of neurotransmitter release. PPR of evoked EPSCs and IPSCs were obtained with 40, 50 and 100ms inter-pulse intervals and by dividing the amplitude of the second EPSC or IPSC by the first one (EPSC2/EPSC1 or IPSC2/IPSC1). Spontaneous postsynaptic currents (sEPSCs and sIPSCs) were analyzed from epochs between sweeps of optically evoked currents. Events were detected automatically using Clampfit 11 and amplitude threshold for event detection were set at $-10 \mathrm{pA}$ and $-15 \mathrm{pA}$ for sEPSC and sIPSC, respectively.

\section{Immunohistochemistry on brain slices}

Nrxn123 WT and Nrxn123 KO mice (P90) were anesthetized using pentobarbital NaCl solution (7 $\mathrm{mg} / \mathrm{mL}$ ) injected intraperitoneally and then perfused intracardially with $20 \mathrm{~mL}$ of PBS followed by $30 \mathrm{~mL}$ of $4 \%$ PFA. The brains were extracted, placed in PFA for $48 \mathrm{~h}$ and then in a $30 \%$ sucrose solution for $48 \mathrm{~h}$. After this period, brains were frozen in $-30^{\circ} \mathrm{C}$ isopentane for $1 \mathrm{~min} .40$ microns thick coronal sections were then cut using a cryostat (Leica CM1800) and placed in antifreeze solution at $-20^{\circ} \mathrm{C}$ until used. For slice immunostaining, after a PBS wash, the tissue was permeabilized, nonspecific binding sites were blocked and slices were incubated overnight with a rabbit anti-TH (1:1000, AB152, Millipore Sigma, USA), a mouse anti-TH (1:1000, Clone LNC1, 
MAB318, Millipore Sigma, USA), a rat anti-DAT (1:2000, MAB369; MilliporeSigma, USA), a rabbit anti-VMAT2 (1:2000, kindly provided by Dr. G.W. Miller, Columbia University) or a chicken anti-GFP (1:1000, GFP-1020; Aves Labs, USA) antibody. Primary antibodies were subsequently detected with rabbit, rat or chicken Alexa Fluor-488-conjugated, 546-conjugated and/or 647-conjugated secondary antibodies (1:500, $2 \mathrm{~h}$ incubation; Invitrogen). Slices were mounted on charged microscope slides (Superfrost/Plus, Fisher Scientific, Canada) and stored at $4^{\circ} \mathrm{C}$ prior to image acquisition.

\section{Fast scan cyclic voltammetry}

Nrxn123 WT, Nrxn123 HET and Nrxn123 KO mice (P90) were used for Fast Scan Cyclic Voltammetry (FSCV) recordings. The animals were anesthetized with halothane, quickly decapitated and the brain harvested. Next, the brain was submersed in ice-cold oxygenated artificial cerebrospinal fluid (aCSF) containing (in $\mathrm{mM}$ ): $\mathrm{NaCl}(125), \mathrm{KCl}(2.5), \mathrm{KH} 2 \mathrm{PO} 4(0.3), \mathrm{NaHCO} 3$ (26), glucose (10), $\mathrm{CaCl} 2$ (2.4), $\mathrm{MgSO} 4$ (1.3) and coronal striatal/nucleus accumbens brain slices of $300 \mu \mathrm{m}$ were prepared with a Leica VT1000S vibrating blade microtome. Once sliced, the tissue was transferred to oxygenated aCSF at room temperature and allowed to recover for at least $1 \mathrm{~h}$. For recordings, slices were put in a custom-made recording chamber superfused with aCSF at 1 $\mathrm{ml} / \mathrm{min}$ and maintained at $32^{\circ} \mathrm{C}$ with a TC-324B single channel heater controller. All solutions were adjusted at $\mathrm{pH} 7.35-7.4,300 \mathrm{mOsm} / \mathrm{kg}$ and saturated with $95 \% \mathrm{O}_{2}-5 \% \mathrm{CO}_{2}$ at least $30-\mathrm{min}$ prior experiment. Electrically-evoked action potential-induced DA overflow was measured by FSCV using a $7 \mu \mathrm{m}$ diameter carbon-fiber electrode crafted as previously described (Martel et al., 2011) and placed into the tissue $\sim 100 \mu \mathrm{m}$ below the surface and a bipolar electrode (Plastics One, Roanoke, VA, USA) was placed $\sim 200 \mu \mathrm{m}$ away. The electrodes were calibrated with $1 \mu \mathrm{M}$ DA in aCSF before and after each recorded slice and the mean of the current values obtained were used to determine the amount of released DA. After use, electrodes were cleaned with isopropyl alcohol 
(Bioshop). The potential of the carbon fiber electrode was scanned at a rate of $300 \mathrm{~V} / \mathrm{s}$ according to a $10 \mathrm{~ms}$ triangular voltage wave $(-400$ to $1000 \mathrm{mV}$ vs $\mathrm{Ag} / \mathrm{AgCl})$ with a $100 \mathrm{~ms}$ sampling interval, using a headstage preamp (Axon instrument, CV 203BU) and a Axopatch 200B amplifier (Axon Instruments, Union City, CA). Data were acquired using a digidata 1440a analog to digital board converter (Axon Instruments) connected to a personal computer using Clampex (Axon Instruments). Slices were left to stabilize for 20-min before any electrochemical recordings. Evaluation of DA release was achieved by sampling 4 different subregions of the dorsal striatum and 4 different subregions of the ventral striatum (nucleus accumbens core and shell) using slices originating from +1.34 to +0.98 using bregma as a reference. After positioning of the bipolar stimulation and carbon fiber electrodes in the tissue, single pulses $(400 \mu \mathrm{A}, 1 \mathrm{~ms})$ were applied to trigger DA release. After sampling of DA release, per pulse ratio experiments were conducted using one spot of the dorsal striatum and one in the nucleus accumbens core. In each spot, a series of single pulses every 2-min for 10-min was collected as a baseline, follow by a triplicate of singlepulse stimuli intercalated with paired pulses $(100 \mathrm{~Hz}$ ) every 2-min (double pulse of $1 \mathrm{~ms}, 400 \mu \mathrm{A}$, with an inter-pulse interval of $100 \mathrm{~ms}$ ). DA release was analyzed as the peak height of DA concentrations (rise time) and DA reuptake was determined from the clearance rate of DA which was assumed to follow Michaelis-Menten kinetics. The time constant Tau (t) was used as an uptake parameter and was calculated based on an exponential fitting applied to all traces with a homemade MATLAB script. The paired pulse ratio was calculated using the peak height of the $1^{\text {st }}$ and $2^{\text {nd }}$ pulse as: $\left(2^{\text {nd }}\right.$ pulse $\left.-1^{\text {st }}\right) / 1^{\text {st }}$.

\section{Behavioral testing}

Before behavioral experiments, mice were transferred from the colony and were housed with a maximum of 4 mice per cage. All mice were handled for 3 consecutive days prior to start of the 
different tests. All tests were performed in the same order as described below. The animals were tested between 10:00AM and 4:30PM.

Rotarod: The accelerating rotarod task was used to assess motor coordination and learning. The apparatus consisted of five rotating rods separated by walls and elevated $30 \mathrm{~cm}$ from the ground. P60-P70 mice were pre-trained on the rod (LE8205, Harvard apparatus) one day before the recording to reach a stable performance. Mice were required to remain on the rod for 1-min at a constant speed of $4 \mathrm{rpm}$ with a maximum of 3 attempts. For the first step of the rotarod testing protocol, the first day of the data acquisition, mice were tested on an accelerated rotation 4-40rpm over a 10-min period for two sessions with an interval of $1 \mathrm{~h}$. The latency to fall was recorded. The same parameters were used on the second test day, but 3 sessions were performed. On the last day of data acquisition, the mice performed 4 sessions with the same previous parameters. A second protocol was also used, in which mice were tested with an accelerated rotation 4-40rpm over a 2min period for all sessions with an interval of $1 \mathrm{~h}$. Each trial per day was analyzed separately and compared between the genotypes.

Locomotor activity and psychostimulant-induced locomotor activity: To evaluate motor behavior, mice were placed in cages (Omnitech Electronics, Inc; USA) designed for activity monitoring using an infrared actimeter (Superflex sensor version 4.6, Omnitech Electronics; 40 x 40 x 30cm) for 20min. Next, $0.9 \%$ saline or the drug treatments were injected intraperitoneally $(10 \mathrm{ml} / \mathrm{kg})$ in a randomized order for the different genotypes. Horizontal activity was scored for 40-min following the injection. To evaluate psychostimulant-induced motor behaviors, the mice were placed in the infrared actimeter cages (Superflex sensor version 4.6, Omnitech Electronics) for 20-min. Then, amphetamine was injected intraperitoneally at $5-\mathrm{mg} / \mathrm{kg}$ (Tocris, UK) or cocaine hydrochloride at 20-mg/Kg (Medisca, cat\# 53-21-4, Canada) in a randomized order for the different genotypes. The total distance (horizontal locomotor activity) was scored for 40-min following the injection. 
Pole test: The test was conducted with a homemade $48-\mathrm{cm}$ metal rod of $1-\mathrm{cm}$ diameter covered with adhesive tape to facilitate traction, placed in a cage. 8-week-old Nrxn123 KO, HET and WT mice were positioned head-up at the top of the pole and the time required to turn (t-turn) and climb down completely was recorded.

Sucrose preference test: Mice were tested for preference of a $2 \%$ sucrose solution, using a two bottles choice procedure. Subjects were housed one per cage all of the test (5 days). Mice were first conditioned with two bottles of water during two days. Then mice were given two bottles, one sucrose $(2 \%)$ and one of tap water. Every $24 \mathrm{~h}$, the amount of sucrose and water consumed was evaluated. To prevent potential location preference of drinking, the position of the bottles was changed every $24 \mathrm{~h}$. The preference for the sucrose solution was calculated as the percentage of sucrose solution ingested relative to the total intake.

\section{Reverse transcription quantitative polymerase chain reaction (RT-qPCR)}

We used RT-qPCR to quantify the amount of mRNA encoding the following genes: gephyrin (Gphn), collybistin (Arhgef 9), GABA-A receptor (Gabra1), neuroligins 1, 2 and 3 (Nlgn1, 2 and3), latrophilins 1, 2 and 3 (Lphn1, 2 and 3), LRRTMs 1, 2, 3, 4 (LRRTM1, 2, 3 and 4), D1R (DRD1) and D2R (DRD2) in striatal brain tissue from P80 Nrxn123 WT and Nrxn123 KO mice. The brains were quickly harvested and the ventral and dorsal striata were microdissected and homogenized in $500 \mu \mathrm{L}$ of trizol. For both, presynaptic and postsynaptic compartment, RNA extraction was performed using RNAeasy Mini Kit (Qiagen, Canada) according to the manufacturer's instructions. RNA integrity was validated using a Bioanalyzer 2100 (Agilent). Total RNA was treated with DNase and reverse transcribed using the Maxima First Strand cDNA synthesis kit with ds DNase (Thermo Fisher Scientific). Gene expression was determined using assays designed with the Universal Probe Library from Roche (www.universalprobelibrary.com). For each qPCR assay, a standard curve was performed to ensure that the efficiency of the assay was between $90 \%$ and 
110\%. The primers used are listed in supplementary Table 1. The Quant Studio qPCR instrument (Thermo Fisher Scientific) was used to detect the amplification level. Relative expression comparison $\left(\mathrm{RQ}=2^{\wedge-\Delta \Delta \mathrm{CT}}\right)$ was calculated using the Expression Suite software (Thermo Fisher Scientific), using GAPDH and $\beta$-Actin as an endogenous control.

\section{Western Blot}

Ventral and dorsal striatum samples were microdissected from Nrxn123 WT and Nrxn123

KO adult mice and then lysed in RIPA buffer (Fisher Scientific, PI89900) containing a protease inhibitor cocktail (P840, Sigma). Homogenized tissue samples were centrifuged at 12000g for 30 min at 40C. Supernatant was collected, and protein quantification was done with BCA reagent (Thermo Scientific Pierce BCA Protein Assay Kit, PI23227). 20 $\mu$ g of each sample was separated on $8 \%$ SDS-PAGE followed by transfer onto a nitrocellulose membrane. Membrane blocking was done with $10 \%$ skimmed milk for $90 \mathrm{~min}$ at RT with gentle shaking. The membranes were incubated overnight at $4^{\circ} \mathrm{C}$ with respective antibodies (Supplementary Table 2) with gentle shaking. Membranes were washed 5 times with TBST buffer for 5 min each time. After this, appropriate secondary antibodies (Supplementary Table 2) were added, and the incubation was performed at RT for 90 min with gentle shaking. Membranes were washed again with TBST buffer for 5 times X $5 \mathrm{~min}$ and developed using the Clarity Western ECL substrate (Bio-Rad, 1004384863). Images were captured on a luminescent image analyzer (GE Healthcare) using Image quant LAS 4000 software. Membranes were stripped and re-probed for $\beta$-actin as a loading control.

\section{Image acquisition with confocal microscopy}

All in vitro fluorescence imaging quantification analyses were performed on images acquired using an Olympus Fluoview FV1000 point-scanning confocal microscope (Olympus, Tokyo, Japan). 
Images were scanned sequentially to prevent non-specific bleed-through signal using 488, 546 and 647-nm laser excitation and a 60X (NA 1:42) oil immersion objective.

\section{Image analysis}

All image quantification was performed using Image-J (National Institute of Health, NIH) software. A background correction was first applied at the same level for every image analyzed before any quantification. A macro developed in-house was used to perform all quantifications.

\section{Statistics}

Data are represented throughout as mean \pm SEM. Statistically significant differences were analyzed using Student's t test, one-way repeated measures ANOVA or two-way ANOVA with Tukey's or Sidak's multiple comparison test $(* \mathrm{p}<0.05 ; * * \mathrm{p}<0.01 ; * * * \mathrm{p}<0.001 ; * * * \mathrm{p}<0.0001)$.

\section{Acknowledgments}

We would like to thank Dr. G. Miller for kindly provided VMAT2 antibody, Willemieke Kouwenhoven for her help with some experiments, the IRIC genomic platform for qRT-PCR analysis, CERVO Québec electron microscopy platform and C.A. Maurice for his strong support. This work was funded by Canadian Institutes of Health Research (CIHR, grant MOP106556) to LE.T. C.D. received a graduate student award from Fond de recherche en santé du Québec (FRQS).

\section{Author contributions}

C.D.: conceptualization, design, acquisition, analysis, validation and interpretation of data (All in vitro results, ICC, GABA uptake, Behavior, IHC, qRT-PCR, Transmission electron microscopy), drafting, revising and editing the manuscript. G. D. C: design, acquisition of 
data, analysis (whole cell patch clamp recording, drafting, revising and editing the manuscript), validation, and interpretation of data. C. VL. D.: acquisition of TEM. S.M.: acquisition and analysis of data (Western Blot). N.G.: viral injections. S.B.N.: help with data analysis (ICC). M-J.: acquisition of data (cell culture), B. D. L.: acquisition of data and analysis (voltammetry). L. Y. C.: conceptualization, design, resources, providing Nrxn123flox/flox mice, genotyping and injection verification, electrophysiology analysis, writing, and review and editing. L-E.T.: conceptualization, resources, funding acquisition, writing, review and editing.

\section{Declaration of interests}

The authors declare no conflicts of interests.

\section{References}

Aoto J, Foldy C, Ilcus SM, Tabuchi K, Sudhof TC (2015) Distinct circuit-dependent functions of presynaptic neurexin-3 at GABAergic and glutamatergic synapses. Nat Neurosci 18:9971007.

Banerjee A, Lee J, Nemcova P, Liu C, Kaeser PS (2020) Synaptotagmin-1 is the Ca(2+) sensor for fast striatal dopamine release. Elife 9.

Banerjee A, Imig C, Balakrishnan K, Kershberg L, Lipstein N, Uronen RL, Wang J, Cai X, Benseler F, Rhee JS, Cooper BH, Liu C, Wojcik SM, Brose N, Kaeser PS (2021) Molecular and functional architecture of striatal dopamine release sites. Neuron.

Berube-Carriere N, Guay G, Fortin GM, Kullander K, Olson L, Wallen-Mackenzie A, Trudeau LE, Descarries L (2012) Ultrastructural characterization of the mesostriatal dopamine innervation in mice, including two mouse lines of conditional VGLUT2 knockout in dopamine neurons. Eur J Neurosci 35:527-538. 
Birgner C, Nordenankar K, Lundblad M, Mendez JA, Smith C, le Greves M, Galter D, Olson L, Fredriksson A, Trudeau LE, Kullander K, Wallen-Mackenzie A (2010) VGLUT2 in dopamine neurons is required for psychostimulant-induced behavioral activation. Proc Natl Acad Sci U S A 107:389-394.

Caille I, Dumartin B, Bloch B (1996) Ultrastructural localization of D1 dopamine receptor immunoreactivity in rat striatonigral neurons and its relation with dopaminergic innervation. Brain Res 730:17-31.

Chen LY, Jiang M, Zhang B, Gokce O, Sudhof TC (2017) Conditional Deletion of All Neurexins Defines Diversity of Essential Synaptic Organizer Functions for Neurexins. Neuron 94:611-625 e614.

Condon MD, Platt NJ, Zhang YF, Roberts BM, Clements MA, Vietti-Michelina S, Tseu MY, Brimblecombe KR, Threlfell S, Mann EO, Cragg SJ (2019) Plasticity in striatal dopamine release is governed by release-independent depression and the dopamine transporter. Nat Commun 10:4263.

Craig AM, Banker G, Chang W, McGrath ME, Serpinskaya AS (1996) Clustering of gephyrin at GABAergic but not glutamatergic synapses in cultured rat hippocampal neurons. J Neurosci 16:3166-3177.

Dal Bo G, St-Gelais F, Danik M, Williams S, Cotton M, Trudeau LE (2004) Dopamine neurons in culture express VGLUT2 explaining their capacity to release glutamate at synapses in addition to dopamine. J Neurochem 88:1398-1405.

Dal Bo G, Berube-Carriere N, Mendez JA, Leo D, Riad M, Descarries L, Levesque D, Trudeau LE (2008) Enhanced glutamatergic phenotype of mesencephalic dopamine neurons after neonatal 6-hydroxydopamine lesion. Neuroscience 156:59-70.

Delignat-Lavaud B, Kano J, Ducrot C, Massé I, Mukherjee S, Giguère N, Moquin L, Lévesque C, Nanni SB, Bourque M-J, Rosa-Neto P, Lévesque D, De Beaumont L, Trudeau L-É 
(2021) The calcium sensor synaptotagmin-1 is critical for phasic axonal dopamine release in the striatum and mesencephalon, but is dispensable for basic motor behaviors in mice. bioRxiv:2021.2009.2015.460511.

Descarries L, Mechawar N (2000) Ultrastructural evidence for diffuse transmission by monoamine and acetylcholine neurons of the central nervous system. Prog Brain Res $125: 27-47$

Descarries L, Bosler O, Berthelet F, Des Rosiers MH (1980) Dopaminergic nerve endings visualised by high-resolution autoradiography in adult rat neostriatum. Nature 284:620622.

Descarries L, Watkins KC, Garcia S, Bosler O, Doucet G (1996) Dual character, asynaptic and synaptic, of the dopamine innervation in adult rat neostriatum: a quantitative autoradiographic and immunocytochemical analysis. J Comp Neurol 375:167-186.

Descarries L, Berube-Carriere N, Riad M, Bo GD, Mendez JA, Trudeau LE (2008) Glutamate in dopamine neurons: synaptic versus diffuse transmission. Brain Res Rev 58:290-302.

Di Chiara G, Imperato A (1988) Drugs abused by humans preferentially increase synaptic dopamine concentrations in the mesolimbic system of freely moving rats. Proc Natl Acad Sci U S A 85:5274-5278.

Ducrot C, Bourque MJ, Delmas CVL, Racine AS, Guadarrama Bello D, Delignat-Lavaud B, Domenic Lycas M, Fallon A, Michaud-Tardif C, Burke Nanni S, Herborg F, Gether U, Nanci A, Takahashi H, Parent M, Trudeau LE (2021) Dopaminergic neurons establish a distinctive axonal arbor with a majority of non-synaptic terminals. FASEB J 35:e21791.

Etherton MR, Blaiss CA, Powell CM, Sudhof TC (2009) Mouse neurexin-1alpha deletion causes correlated electrophysiological and behavioral changes consistent with cognitive impairments. Proc Natl Acad Sci U S A 106:17998-18003. 
Fasano C, Thibault D, Trudeau LE (2008) Culture of postnatal mesencephalic dopamine neurons on an astrocyte monolayer. Curr Protoc Neurosci Chapter 3:Unit 321.

Gerfen CR, Surmeier DJ (2011) Modulation of striatal projection systems by dopamine. Annu Rev Neurosci 34:441-466.

Graf ER, Zhang X, Jin SX, Linhoff MW, Craig AM (2004) Neurexins induce differentiation of GABA and glutamate postsynaptic specializations via neuroligins. Cell 119:1013-1026.

Hata Y, Butz S, Sudhof TC (1996) CASK: a novel dlg/PSD95 homolog with an N-terminal calmodulin-dependent protein kinase domain identified by interaction with neurexins. J Neurosci 16:2488-2494.

Ichtchenko K, Hata Y, Nguyen T, Ullrich B, Missler M, Moomaw C, Sudhof TC (1995) Neuroligin 1: a splice site-specific ligand for beta-neurexins. Cell 81:435-443.

Ko J, Fuccillo MV, Malenka RC, Sudhof TC (2009) LRRTM2 functions as a neurexin ligand in promoting excitatory synapse formation. Neuron 64:791-798.

Kornau HC, Seeburg PH, Kennedy MB (1997) Interaction of ion channels and receptors with PDZ domain proteins. Curr Opin Neurobiol 7:368-373.

Li J, Ashley J, Budnik V, Bhat MA (2007) Crucial role of Drosophila neurexin in proper active zone apposition to postsynaptic densities, synaptic growth, and synaptic transmission. Neuron 55:741-755.

Liu C, Kershberg L, Wang J, Schneeberger S, Kaeser PS (2018) Dopamine Secretion Is Mediated by Sparse Active Zone-like Release Sites. Cell 172:706-718 e715.

Luo F, Sclip A, Jiang M, Sudhof TC (2020) Neurexins cluster Ca(2+) channels within the presynaptic active zone. EMBO J 39:e103208.

Luo F, Sclip A, Merrill S, Sudhof TC (2021) Neurexins regulate presynaptic GABAB-receptors at central synapses. Nat Commun 12:2380. 
Martel P, Leo D, Fulton S, Berard M, Trudeau LE (2011) Role of Kv1 potassium channels in regulating dopamine release and presynaptic D2 receptor function. PLoS One 6:e20402.

Matsuda W, Furuta T, Nakamura KC, Hioki H, Fujiyama F, Arai R, Kaneko T (2009) Single nigrostriatal dopaminergic neurons form widely spread and highly dense axonal arborizations in the neostriatum. J Neurosci 29:444-453.

Mendez JA, Bourque MJ, Dal Bo G, Bourdeau ML, Danik M, Williams S, Lacaille JC, Trudeau LE (2008) Developmental and target-dependent regulation of vesicular glutamate transporter expression by dopamine neurons. J Neurosci 28:6309-6318.

Missler M, Zhang W, Rohlmann A, Kattenstroth G, Hammer RE, Gottmann K, Sudhof TC (2003) Alpha-neurexins couple Ca2+ channels to synaptic vesicle exocytosis. Nature 423:939-948.

Ogura T, Ogata M, Akita H, Jitsuki S, Akiba L, Noda K, Hoka S, Saji M (2005) Impaired acquisition of skilled behavior in rotarod task by moderate depletion of striatal dopamine in a pre-symptomatic stage model of Parkinson's disease. Neurosci Res 51:299-308.

Robinson BG, Cai X, Wang J, Bunzow JR, Williams JT, Kaeser PS (2019) RIM is essential for stimulated but not spontaneous somatodendritic dopamine release in the midbrain. Elife 8.

Sanchez G, Varaschin RK, Bueler H, Marcogliese PC, Park DS, Trudeau LE (2014) Unaltered striatal dopamine release levels in young Parkin knockout, Pink1 knockout, DJ-1 knockout and LRRK2 R1441G transgenic mice. PLoS One 9:e94826.

Schultz W (2007) Multiple dopamine functions at different time courses. Annu Rev Neurosci 30:259-288.

Sorensen G, Rickhag M, Leo D, Lycas MD, Ridderstrom PH, Weikop P, Lilja JH, Rifes P, Herborg F, Woldbye D, Wortwein G, Gainetdinov RR, Fink-Jensen A, Gether U (2021) Disruption of the PDZ-domain binding motif of the dopamine transporter uniquely alters 
nanoscale distribution, dopamine homeostasis and reward motivation. J Biol Chem:101361.

Stuber GD, Hnasko TS, Britt JP, Edwards RH, Bonci A (2010) Dopaminergic terminals in the nucleus accumbens but not the dorsal striatum corelease glutamate. J Neurosci 30:82298233.

Sulzer D, Joyce MP, Lin L, Geldwert D, Haber SN, Hattori T, Rayport S (1998) Dopamine neurons make glutamatergic synapses in vitro. J Neurosci 18:4588-4602.

Surmeier DJ, Graves SM, Shen W (2014) Dopaminergic modulation of striatal networks in health and Parkinson's disease. Curr Opin Neurobiol 29:109-117.

Tabuchi K, Sudhof TC (2002) Structure and evolution of neurexin genes: insight into the mechanism of alternative splicing. Genomics 79:849-859.

Tritsch NX, Ding JB, Sabatini BL (2012) Dopaminergic neurons inhibit striatal output through non-canonical release of GABA. Nature 490:262-266.

Tritsch NX, Granger AJ, Sabatini BL (2016) Mechanisms and functions of GABA co-release. Nat Rev Neurosci 17:139-145.

Tritsch NX, Oh WJ, Gu C, Sabatini BL (2014) Midbrain dopamine neurons sustain inhibitory transmission using plasma membrane uptake of GABA, not synthesis. Elife 3:e01936.

Ullrich B, Ushkaryov YA, Sudhof TC (1995) Cartography of neurexins: more than 1000 isoforms generated by alternative splicing and expressed in distinct subsets of neurons. Neuron $14: 497-507$.

Ushkaryov YA, Petrenko AG, Geppert M, Sudhof TC (1992) Neurexins: synaptic cell surface proteins related to the alpha-latrotoxin receptor and laminin. Science 257:50-56.

Wang A, Xiang YY, Yang BB, Lu WY (2019) Neurexin-1alpha regulates neurite growth of rat hippocampal neurons. Int J Physiol Pathophysiol Pharmacol 11:115-125. 
Yorgason JT, Espana RA, Jones SR (2011) Demon voltammetry and analysis software: analysis of cocaine-induced alterations in dopamine signaling using multiple kinetic measures. $\mathbf{J}$ Neurosci Methods 202:158-164.

Zhang H, Sulzer D (2004) Frequency-dependent modulation of dopamine release by nicotine. Nat Neurosci 7:581-582.

Zhou QY, Palmiter RD (1995) Dopamine-deficient mice are severely hypoactive, adipsic, and aphagic. Cell 83:1197-1209. 


\section{Supplementary figures and legends}
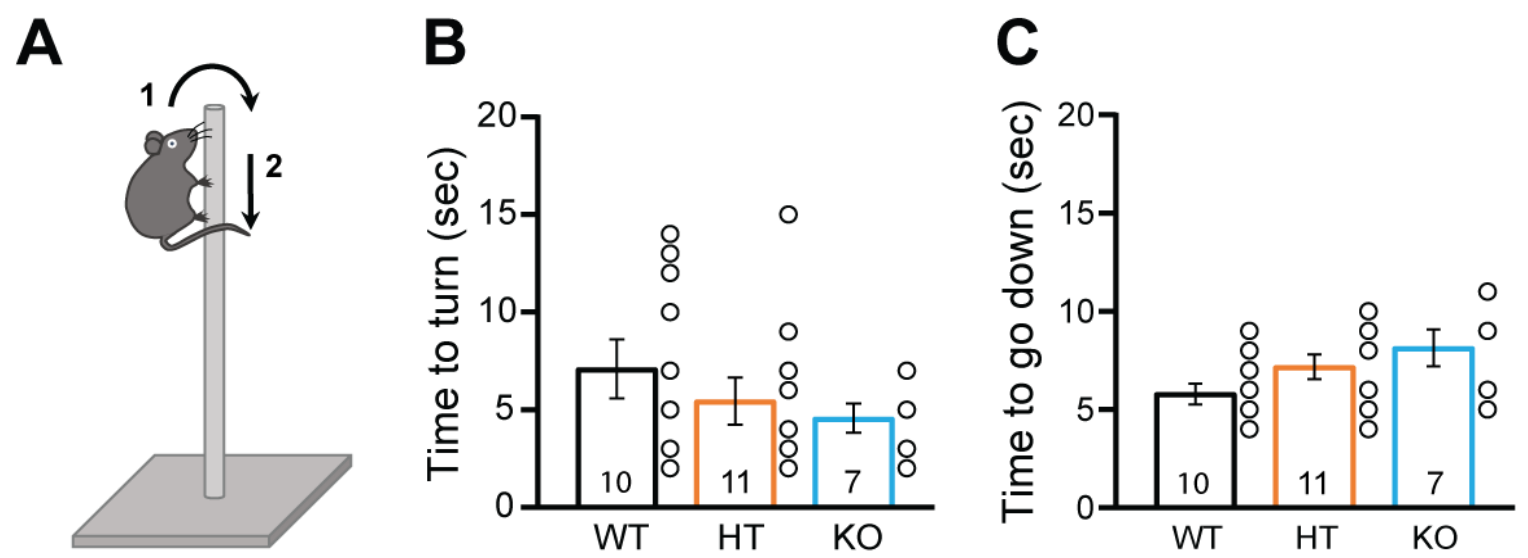

Supplementary figure 1 - No motor deficit with the pole test in DAT::NrxnsKO mice. Aschematic representation of the pole test procedure. B- Summary graph of the time to turn shows no genotype effect $(\mathrm{WT}=7.10 \pm 1.50 \mathrm{sec} ; \mathrm{HET}=5.45 \pm 1.20 \mathrm{sec} ; \mathrm{KO}=4.57 \pm 0.75 \mathrm{sec})$. C- Summary graph of the time to go down shows no genotype effect $(\mathrm{WT}=5.80 \pm 0.53 \mathrm{sec} ; \mathrm{HET}=7.18 \pm 0.62 \mathrm{sec}$; $\mathrm{KO}=8.14 \pm 0.93 \mathrm{sec})(\mathrm{WT} \mathrm{n}=10 ;$ HET $\mathrm{n}=11$ and $\mathrm{KO} \mathrm{n}=7$ mice $)$.

\section{Striatum Electrically Evoked DA Release}
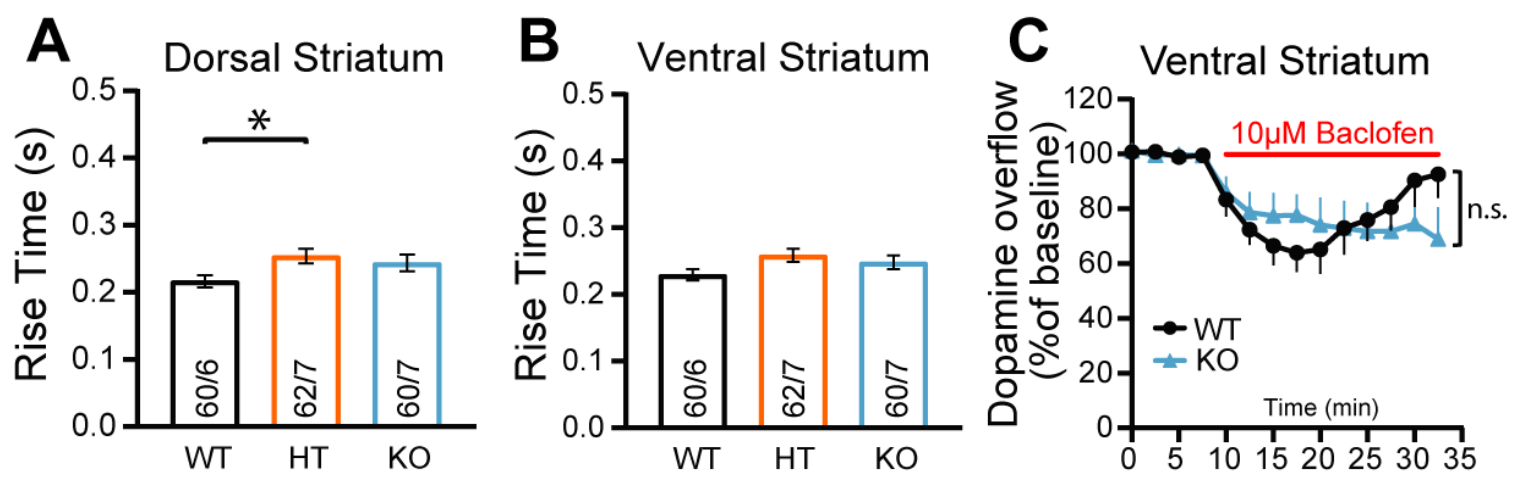

Supplementary figure 2 - No change in GABA $_{B}$ receptor modulation of DA release after conditional deletion of all neurexins. A- Summary graph of the rise time of electrically evoked DA overflow in the dorsal striatum showing a genotype difference (HET versus WT : $0.25 \pm 0.01 \mathrm{~s}$ 
compared to $0.22 \pm 0.01 \mathrm{~s}$, respectively). B- Summary graph of the rise time of electrically evoked DA overflow in the ventral striatum shows no genotype effect. C- Plot of relative peak DA overflow and its modulation by the $\mathrm{GABA}_{\mathrm{B}}$ agonist baclofen in the ventral striatum. No difference between WT and KO mice was observed.

A V. Striatum Electrically Evoked IPSC<smiles>BrC1CCCCC1</smiles><smiles>CC1CCCCC1C</smiles>
$\mathrm{HT}$ I

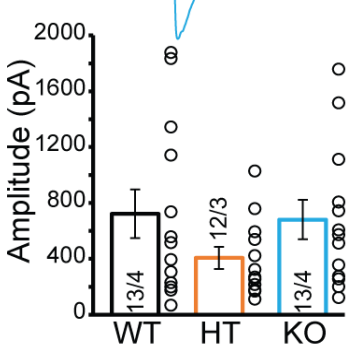

C D. Striatum Electrically Evoked IPSC

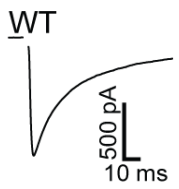
HT
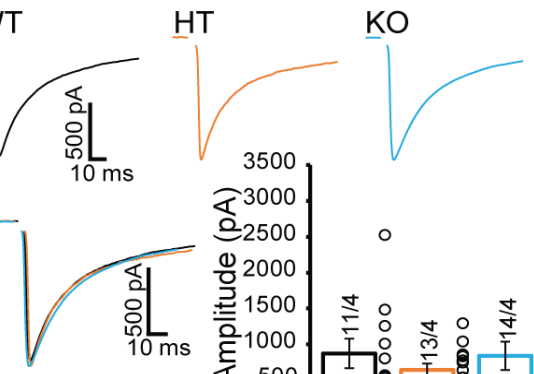

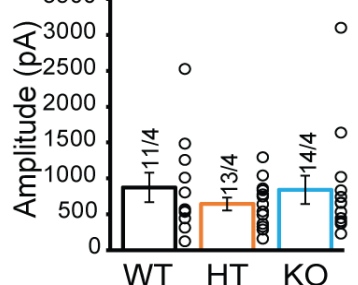

B V. Striatum Electrically Evoked EPSC
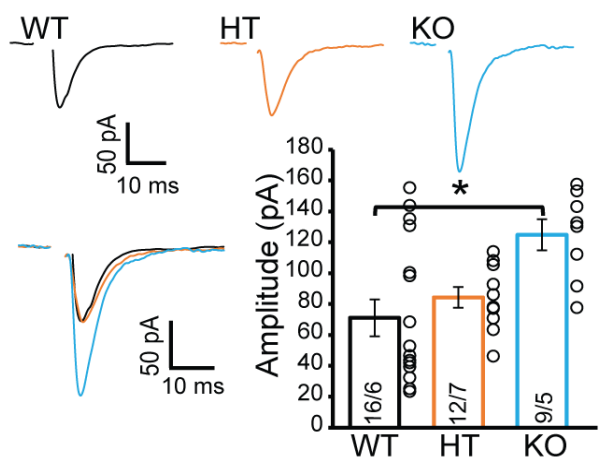

D D. Striatum Electrically Evoked EPSC
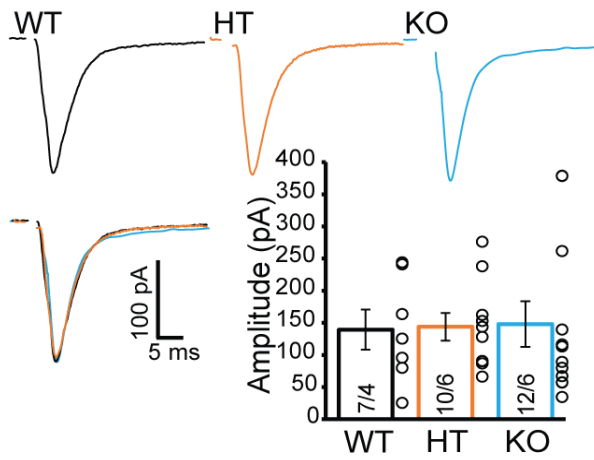

\section{Supplementary figure 3 - Electrically evoked EPSC amplitude is increased in the vSTR of}

\section{DAT::NrxnsKO mice.}

A- Representative traces (top) of IPSCs elicited by electrical-stimulation (e-IPSC) and recorded in ventral striatal MSNs. Summary graph of e-IPSC amplitudes (bottom) shows no genotype effect (Peak Amplitude: $\mathrm{WT}=-722.64 \pm 174.29$ pA, $\mathrm{HT}=-406.01 \pm 80.15 \mathrm{pA}, \mathrm{KO}=-680.89 \pm 141.06$, Mean \pm SEM). B- Representative traces (top) of EPSCs elicited by electrical-stimulation (e-EPSC) 
and recorded in ventral striatal MSNs. Summary graph of e-EPSC amplitudes (bottom) shows an increased amplitude in the KO mice compared to WT (Peak Amplitude: WT = -71.03 $\pm 11.9 \mathrm{pA}$, $\mathrm{HT}=-84.2 \pm 6.76 \mathrm{pA}, \mathrm{KO}=-124.8 \pm 10.15$, Mean $\pm \mathrm{SEM}$ ). $\mathrm{C}$ - Representative traces (top) e-IPSCs recorded in dorsal striatal MSNs. Summary graph of e-IPSC amplitudes (bottom) shows no genotype effect. D- Representative traces (top) of e-EPSCs recorded in dorsal striatal MSNs. Summary graph of e-EPSC amplitudes (bottom) shows no genotype effect. Data in summary graphs are presented as mean \pm SEM; statistical comparisons were performed with One-Way ANOVA $(* \mathrm{P}<0.05 ; * * \mathrm{P}<0.01 ; * * * \mathrm{P}<0.001 ;$ non-significant comparisons are not identified). Tukey's correction was used for all multiple comparisons.
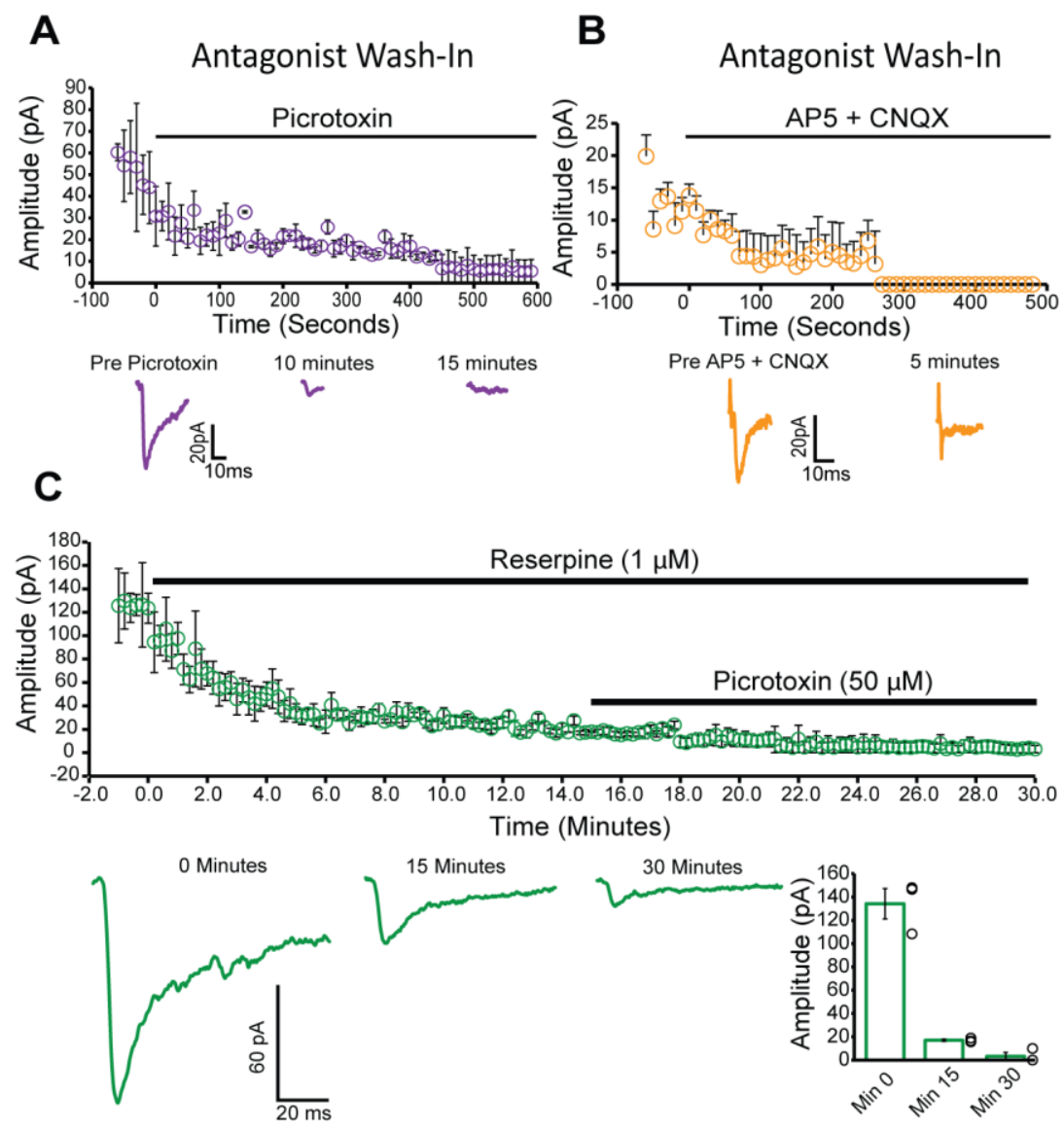


\section{Supplementary figure 4 - Pharmacological properties of o-IPSCs and o-EPSCs recorded}

from MSNs in acute ventral striatal slices. A- Graph showing the amplitude of o-IPSCs recorded in ventral striatal MSNs before and after incubation with the $\mathrm{GABA}_{\mathrm{A}}$ channel receptor pore blocker Picrotoxin. B- Graph showing the amplitude of o-EPSCs recorded in ventral striatal MSNs before and after incubation with the AMPA and NMDA receptor blockers AP5 and CNQX, respectively. C-Graph showing the amplitude of o-IPSCs recorded in ventral striatal MSNs before and after incubation with the VMAT2 blocker reserpine, followed by Picrotoxin.
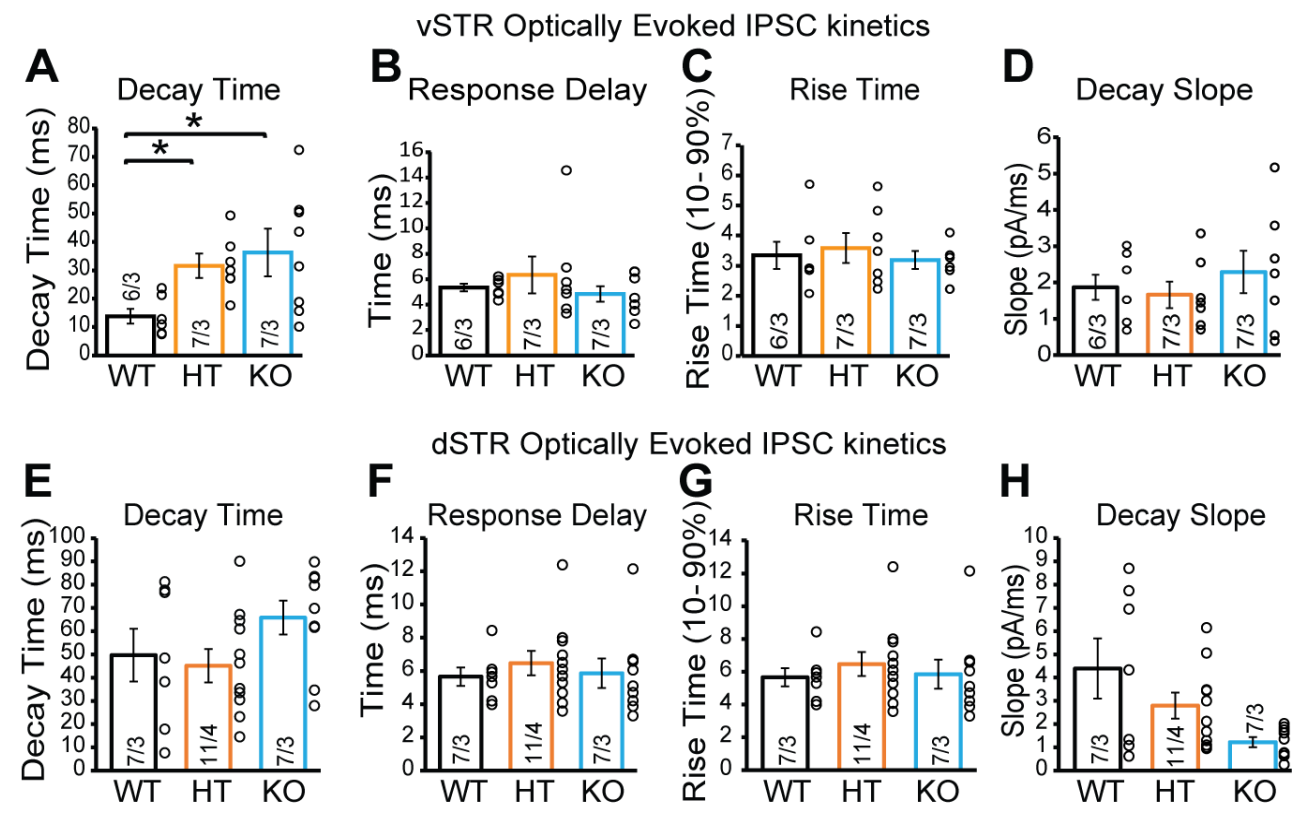

\section{Supplementary figure 5 -Removal of neurexins increases oIPSC decay time in the ventral but}

not the dorsal striatum. A to D - Summary graphs of o-IPSC kinetics recorded in ventral striatal MSNs. From left to right: decay time (A) (Time [90 - 10\%]: WT $=13.8 \pm 2.5 \mathrm{~ms}, \mathrm{HT}=31.6 \pm 4.3$ $\mathrm{ms}, \mathrm{KO}=36.2 \pm 8.4 \mathrm{~ms}$, Mean $\pm \mathrm{SEM}$ ), response delay (latency from stimulation to peak response) (B), rise time (C), and decay slope (D). E to $\mathbf{H}$ - Summary graphs of o-IPSC kinetics recorded in 
dorsal striatal MSNs; (from left to right) decay time $(\mathbf{E})$, response delay $(\mathbf{F})$, rise time $(\mathbf{G})$, and decay slope $(\mathbf{H})$.

A D. Striatum IPSC
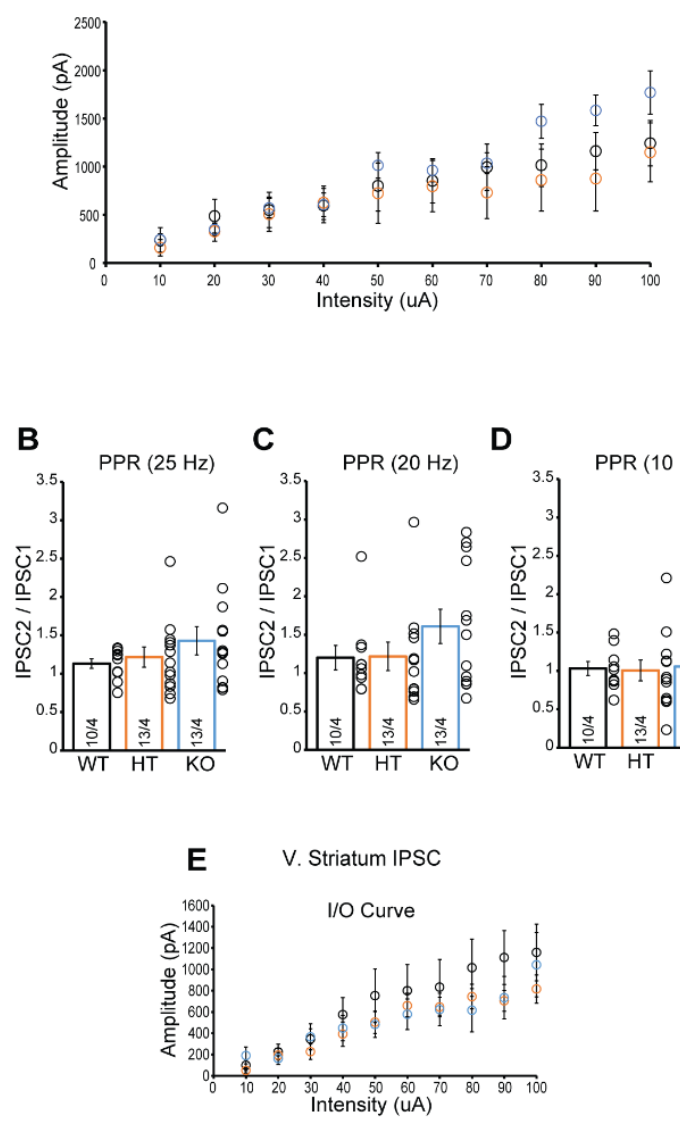

V. Striatum IPSC PPR
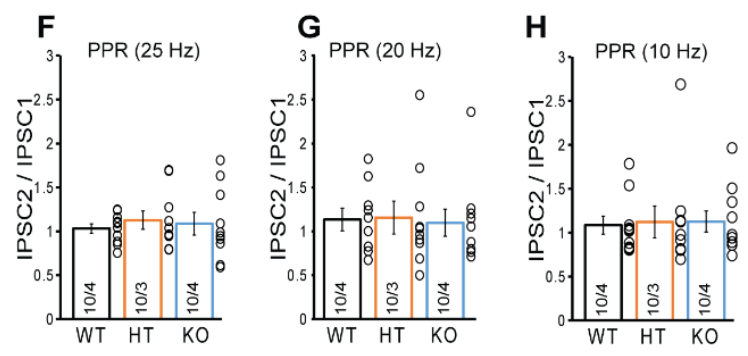

I
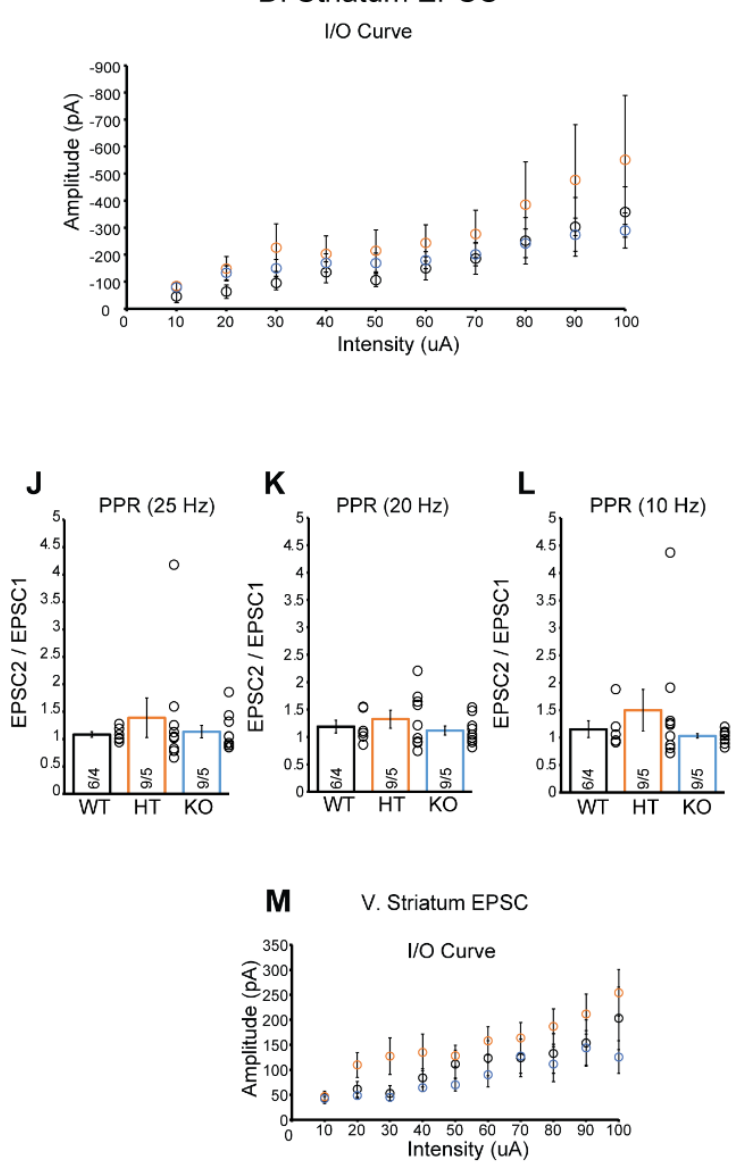

V. Striatum EPSC PPR

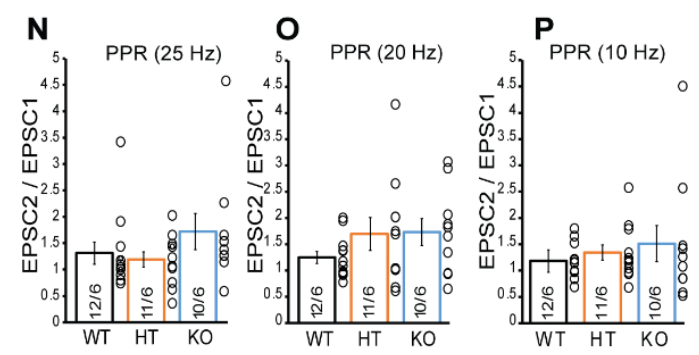

\section{Supplementary figure 6 - No change in synaptic plasticity of electrically-evoked IPSCs and}

EPSCs after conditional deletion of all Nrxns in DA neurons - A. Scatterplot of IPSC input- 
output relationship in MSNs of the dorsal striatum of WT, HT, and KO mice. B. Summary graph of GABAergic IPSC paired-pulse ratio (PPR) in MSNs of the dorsal striatum; two electrical pulses were delivered with an inter-stimulation interval (ISI) of $40 \mathrm{~ms}(25 \mathrm{~Hz})$. C. Same as in B; ISI = 50 ms $(20 \mathrm{~Hz})$. D. Same as in $\mathbf{B}$ and $\mathbf{C}$; ISI $=100 \mathrm{~ms}(10 \mathrm{~Hz})$. E. Scatterplot of IPSC input-output relationship in MSNs of the ventral striatum. F. Summary graph of GABAergic IPSC paired-pulse ratio (PPR) in MSNs of the ventral striatum; two electrical pulses were delivered with an interstimulation interval (ISI) of $40 \mathrm{~ms}(25 \mathrm{~Hz})$. G. Same as in F; ISI $=50 \mathrm{~ms}(20 \mathrm{~Hz})$. H. Same as in $\mathbf{F}$ and G; ISI = $100 \mathrm{~ms}(10 \mathrm{~Hz})$. I. Scatterplot of EPSC input-output relationship in MSNs of the dorsal striatum. J. Summary graph of glutamatergic paired-pulse ratio (PPR) in MSNs of the dorsal striatum; two electrical pulses were delivered with an inter-stimulation interval (ISI) of $40 \mathrm{~ms}$ (25 Hz). K. Same as in J; ISI $=50 \mathrm{~ms}(20 \mathrm{~Hz})$. L. Same as in $\mathbf{K}$ and $\mathbf{J}$; ISI $=100 \mathrm{~ms}(10 \mathrm{~Hz})$. M. Scatterplot of EPSC input-output relationship in MSNs of the ventral striatum. N. Summary graph of EPSC paired-pulse ratio (PPR) in MSNs of the ventral striatum; two electrical pulses were delivered with an inter-stimulation interval (ISI) of $40 \mathrm{~ms}(25 \mathrm{~Hz})$. O. Same as in N; ISI = $50 \mathrm{~ms}$ $(20 \mathrm{~Hz})$. P. Same as in N and $\mathbf{O}$; ISI $=100 \mathrm{~ms}(10 \mathrm{~Hz})$.
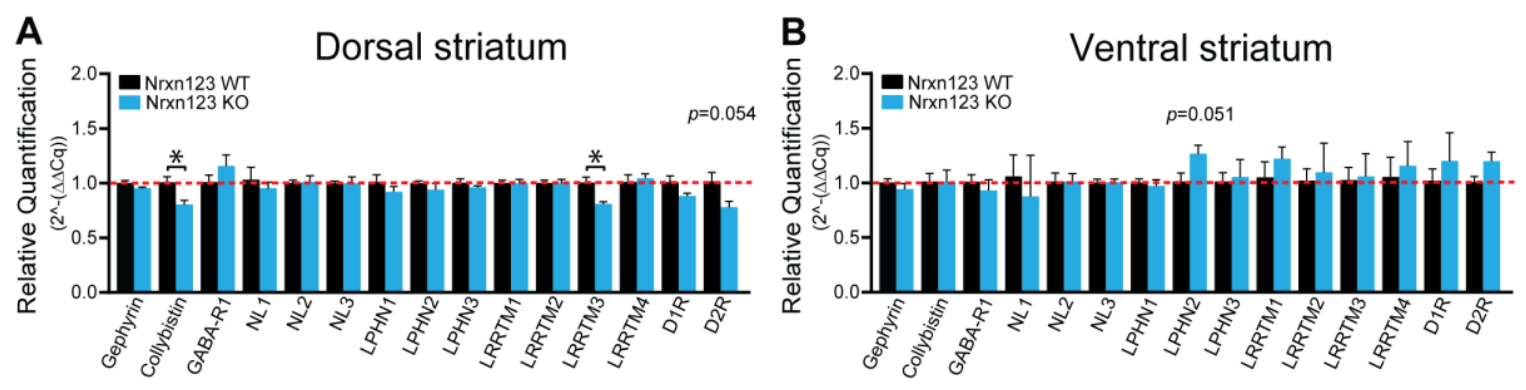

\section{Supplementary figure 7 - Gene expression profile in target cells of DA neurons after} conditional deletion of Nrxn123. A and $\mathbf{B}$ - Relative changes of mRNA levels measured by RTqPCR, from ventral and dorsal striatum tissue: Gephyrin (Gphn), Collybistin (Arhgef 9), GABAA receptor (Gabra1), Neuroligins 1, 2 and 3 (Nlgn1, 2 and 3), Latrophilins 1, 2 and 3 (Lphn1, 2 and 
3), LRRTMs 1, 2, 3, 4 (LRRTM1, 2, 3 and 4), D1R (DRD1) and D2R (DRD2) in brain tissue from P80 DAT::NrxnsWT, and DAT::NrxnsKO mice.

\section{Ventral Striatum}
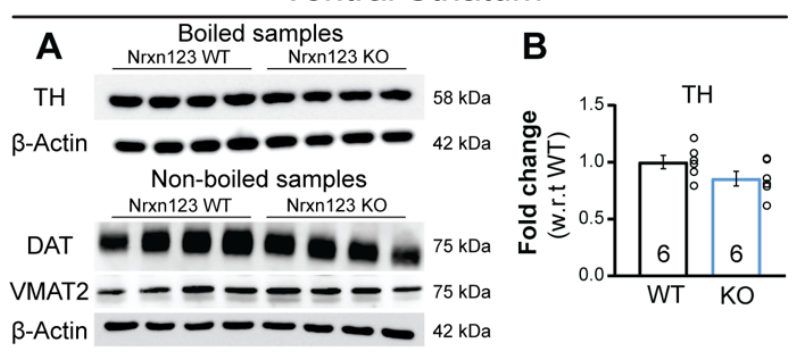

C
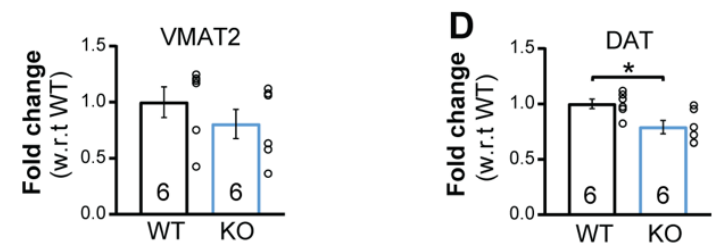

Dorsal Striatum
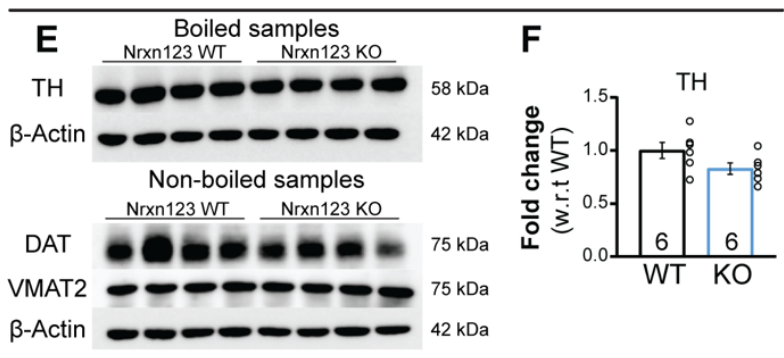

G
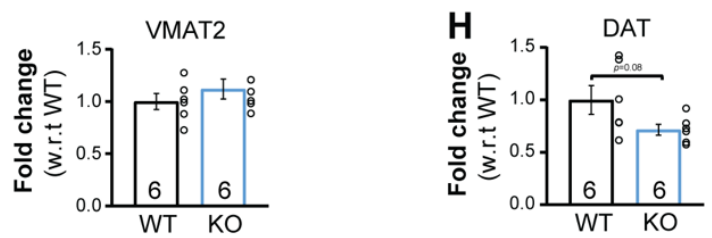

\section{Supplementary figure 8 - Decrease of DAT protein expression in DA neurons from}

DAT::NrxnsKO mice. A- Representative western blots illustrating TH, DAT, VMAT2 and $\beta$-actin protein from total striatum homogenates of adult mice. B to D- Immunoblot quantifying relative protein levels (fold change compared to controls) for TH (B), VMAT2 (C) and DAT (D) (n = 6 DAT::NrxnsWT, HET and KO mice). E- Representative western blots illustrating TH, DAT, VMAT2 or $\beta$-actin from total striatum homogenates of adult mice. $\mathbf{F}$ to $\mathbf{H}$ - Immunoblot quantifying 
relative protein levels (fold change compared to controls) for TH (F), VMAT2 $(\mathbf{G})$ and DAT $(\mathbf{H})$

(n = 6 DAT::NrxnsWT, HET and KO mice). Error bars represent \pm S.E.M. (ns, non-significant; *, $\mathrm{p}<0.05 ; * *, \mathrm{p}<0.01 ; * * *, \mathrm{p}<0.001 ; * * * *, \mathrm{p}<0.0001)$

\section{Supplementary table 1 - qPCR primers for ventral and dorsal striatum}

\begin{tabular}{|c|c|c|c|}
\hline Gene & Oligo Forward & Oligo Reverse & Reference Sequences \\
\hline Gphn & cctcgcccagaataccac & gacggctgctcatctgattac & NM_145965.2, NM_172952.3 \\
\hline Arhgef9 & tgagaaaagcttctaaacagaaagg & gtactggccetggtttaacg & NM_001033329.3 \\
\hline Gabra1 & cgatcctctctcccacactt & tttcttcatcacgggcttg & NM_010250.5 \\
\hline Nlgn1 & ctatcggcttggggtacttg & caaggagcccgtagtttcct & NM_138666.3, \\
& & & NM_001163387.1 \\
\hline Nlgn2 & gaggaaagggggaatctctg & ggccgtgggaaggtaagt & NM_198862.2 \\
\hline Nlgn3 & gaagggagggctccaagat & ggtccttctccttggtctgat & NM_172932.4 \\
\hline Adgrl1 & cagtacgactgtgtcccttacatc & cagactgatgctctgactcatgt & NM_181039.2 \\
\hline Adgrl2 & gagctgaagccgagtgagaa & cctgcatgtcttctctcgttt & NM_001081298.1 \\
\hline Adgrl3 & aacaacctccttcagccaca & cgcagttgatcacttgtcgt & NM_001347369.1 \\
\hline Lrrtm1 & cgccctgcatataattagcc & gaagcgctgggtcagaaa & NM_028880.3 \\
\hline Lrrtm2 & gtagggacaaaaacctgtttgatt & aagtaggaagccagttgtggtc & NM_178005.4 \\
\hline Lrrtm3 & gaccctgcacctatagcaaatc & tgccagaaaggttgacacat & NM_178678.4 \\
\hline Lrrtm4 & gccatgattctcctggtgat & tgagtgctgttggagttgtttc & NM_001134743.1 \\
\hline Drd1 & aggttgagcaggacatacgc & tggctacggggatgtaaaag & NM_010076.3 \\
\hline Drd2 & gatgcttgccattgttcttg & attcaggatgtgcgtgatga & NM_010077.2 \\
\hline Gapdh & tgtccgtcgtggatctgac & cctgcttcaccaccttcttg & NM_008084.2 \\
\hline Actb & aaggccaaccgtgaaaagat & gtggtacgaccagaggcatac & NM_007393.3 \\
\hline
\end{tabular}




\section{Supplementary table 2 - Antibodies for Western Blot}

\begin{tabular}{|c|c|c|c|c|}
\hline Antibody & Catalog numbers & Raised in & $\begin{array}{c}\text { Dilution } \\
\text { used }\end{array}$ & RRID \\
\hline DAT & $\begin{array}{c}\text { MAB369 } \\
\text { (Millipore) }\end{array}$ & Rat & $1: 1000$ & AB_2190413 \\
\hline TH & $\begin{array}{c}\text { MAB318 } \\
\text { (Millipore) }\end{array}$ & Mouse & $1: 1000$ & AB_2201528 \\
\hline VMAT2 & $\begin{array}{c}\text { Kind gift from Dr. Gary Miller, } \\
\text { Emory University, USA }\end{array}$ & Rabbit & $1: 5000$ & NA \\
\hline$\beta$ Actin & A3854(Sigma) & $\begin{array}{c}\text { Purified from } \\
\text { hybridoma } \\
\text { cell culture }\end{array}$ & $1: 15000$ & AB_262011 \\
\hline
\end{tabular}

\begin{tabular}{|c|c|c|c|}
\hline Antibody & Catalog number & Dilution used & RRID \\
\hline $\begin{array}{c}\text { Peroxidase-conjugated } \\
\text { AffiniPure Goat Anti-Rat } \\
\text { IgG (H+L) }\end{array}$ & $\begin{array}{c}711-035-152 \\
\text { (Cedarlane) }\end{array}$ & $1: 5000$ & AB_10015282 \\
\hline $\begin{array}{c}\text { Peroxidase-conjugated } \\
\text { AffiniPure Goat Anti-Rabbit } \\
\text { IgG (H+L) }\end{array}$ & $\begin{array}{c}112-035-003 \\
\text { (Cedarlane) }\end{array}$ & $1: 5000$ & AB_2338128 \\
\hline $\begin{array}{c}\text { Peroxidase-conjugated } \\
\text { AffiniPure Goat Anti-Mouse } \\
\text { IgG (H+L) }\end{array}$ & $\begin{array}{c}115-035-146 \\
(\text { Cedarlane })\end{array}$ & $1: 5000$ & AB_2307392 \\
\hline
\end{tabular}

